
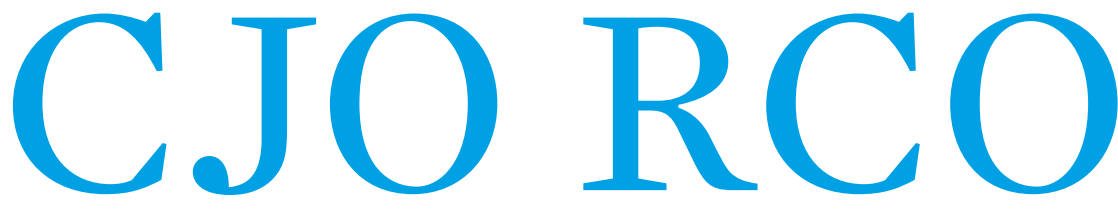

CANADIAN JOURNAL of OPTOMETRY | REVUE CANADIENNE D'OPTOMÉTRIE EST. 1939 VOLUME 82 SUPPLEMENT 1, 2020

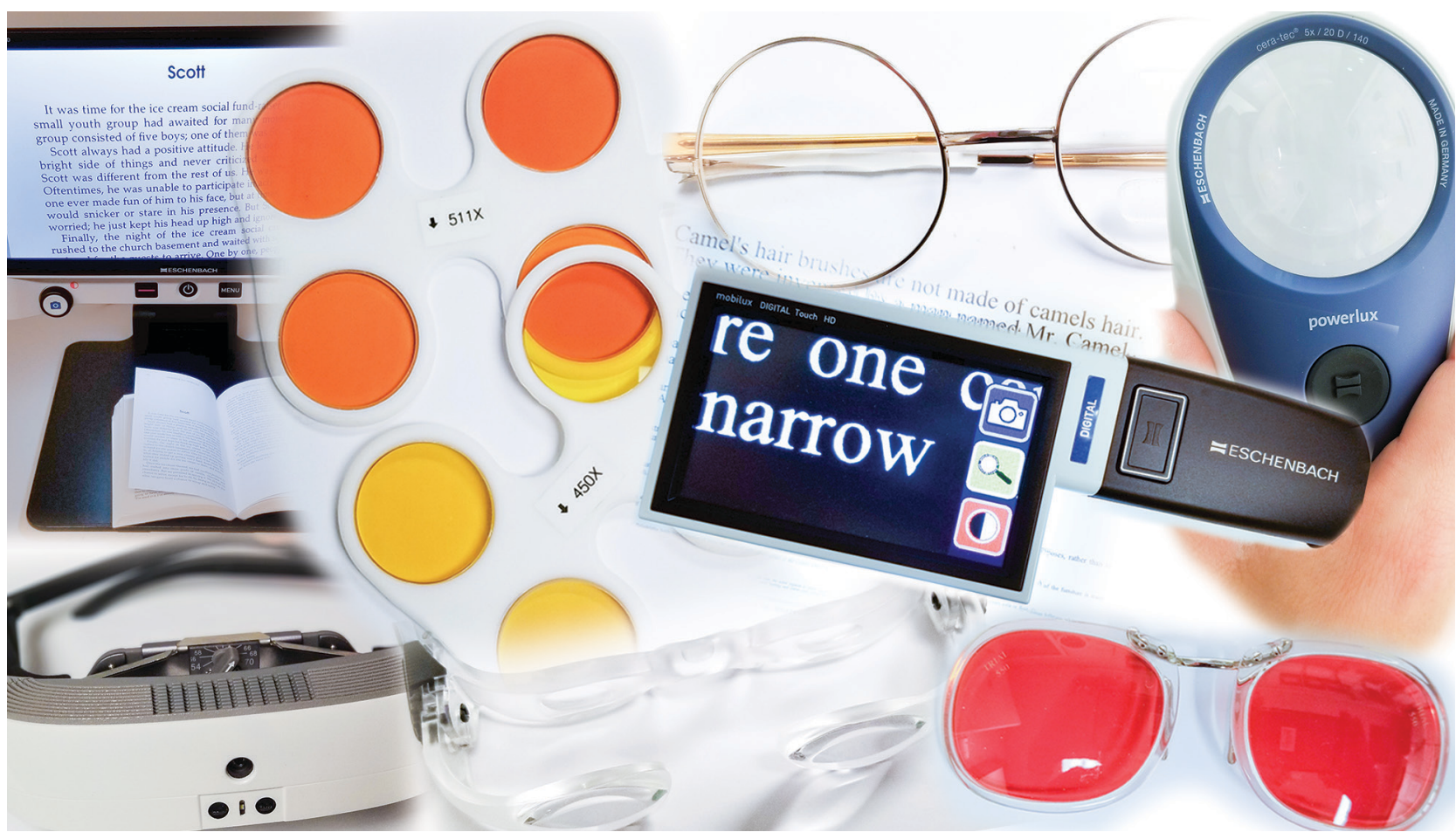

CLINICAL GUIDELINES

2020 CAO Clinical Practice Guideline: Optometric Low Vision Rehabilitation 



\section{CAO Clinical Practice Guideline: Optometric Low Vision Rehabilitation}

The Low Vision CPG

Working group members are:

Susan J. Leat, BSc(Hons), PhD, FCOptom, FAAO

School of Optometry and Vision Science,

University of Waterloo

Alexis Keeling,

BSc, BScEd, OD

Dr. Alexis Keeling Optometry

Tammy Labreche, BSc(Hons), OD, FAAO

School of Optometry and Vision Science,

University of Waterloo

Julie-Andrée Marinier, BSc, OD, MSc

École d'optométrie,

Université de Montréal

Rajan Mistry,

BSc(Hons), OD

Alberta Eye Health Clinic

Michael Nelson, OD, FAAO

Waverley Eye Care Centre

Abraham Yuen,

BSc(Hons), OD

FYidoctors Markham/

Richmond University

Vision Care

\section{CONTENTS}

1. Abstract

2. Introduction

2.1 Definitions

2.1.1 Low Vision

2.1.2 Low Vision Rehabilitation

2.2 Epidemiology

2.3 Impact of Visual Impairment

2.4 The Need for Low Vision Rehabilitation and the Role of Optometrists

2.5 The Effectiveness of Low Vision Rehabilitation

2.5.1 Low Vision Rehabilitation provided by optometrists

2.6 Models of Low Vision Rehabilitation

3. Optometric Low Vision Rehabilitation

3.1 Low Vision Rehabilitation - Assessment

3.1.1 Case History

3.1.2 Visual Acuity

3.1.3 Refraction

3.1.4 Ocular Alignment and Motility

3.1.5 Contrast Sensitivity

3.1.6 Visual Fields

3.1.7 Colour Vision

3.1.8 Glare Testing

3.1.9 Ocular Health Assessment

3.1.10 Additional assessments

3.1.11 Creation of the Initial Rehabilitation Plan

3.2 Low Vision Rehabilitation - Management

3.2.1 Management of Central Vision Loss

3.2.2 Management of Contrast Sensitivity Loss

3.2.3 Management of Peripheral Field Loss

3.2.4 Management of Nystagmus

3.2.5 Lighting Requirements

3.2.6 Other Interventions and Considerations

3.2.7 Non-visual Factors Affecting the Low Vision

Rehabilitation Outcome

4. Conclusion 
Acknowledgements

Appendices

Appendix A: Provincial Health Funding for Low Vision

Assessments and Devices

Appendix B: Summary of Systematic Reviews of Low Vision Interventions

Appendix C: Levels of Low Vision Service

Appendix D: Estimating Magnification

Appendix E: Decentration and Base-in Prism Requirements for Microscopes

Appendix F: Optics of Hand Magnifiers, Stand Magnifiers and Telemicroscopes

Appendix G: Eccentric Viewing Training

Appendix H: Placement of Prisms for Peripheral Awareness in Hemianopia

Appendix I: Converting Lux to Lumens

References 


\section{ABSTRACT}

The purpose of the Low Vision Clinical Practice Guideline for Canadian Optometrists is to assist them in providing the best level of care in the management of patients with low vision. The guideline is based on current best evidence regarding optometric low vision rehabilitation as interpreted by an expert panel. The writing group includes optometrists from academia and private practice, representing various regions across Canada. This guideline will aid optometrists in identifying patients who require low vision rehabilitation and recommends appropriate assessment and management.

As primary eye care providers, optometrists are optimally trained and qualified to identify and manage patients who would benefit from low vision rehabilitation. Optometrists, based on their geographical presence in local communities, are also well positioned to provide initial rehabilitation in a timely, effective manner, and to initiate referral for more comprehensive rehabilitation if required.

\section{INTRODUCTION}

\subsection{DEFINITIONS}

Table 1: Definitions and abbreviations

\begin{tabular}{|c|c|}
\hline CPS & $\begin{array}{l}\text { Critical print size. The smallest print at which maximum }{ }^{1,2} \text { or near maximum reading speed is } \\
\text { attained }^{3} \text {. CPS is distance dependent, which must be specified. It can be written as a visual acuity } \\
\text { fraction (distance as numerator and M print as denominator). }\end{array}$ \\
\hline $\mathrm{CS}$ & Contrast sensitivity \\
\hline EVP & $\begin{array}{l}\text { Equivalent Viewing Power. This is used to describe the equivalent power of optical devices } \\
\text { and systems, such as stand magnifiers (which are used in combination with a reading add) } \\
\text { or telemicroscopes. It is the power of a microscope which would give the same equivalent } \\
\text { magnification or power. }\end{array}$ \\
\hline $\operatorname{logMAR}$ & Logarithm of the Minimum Angle of Resolution \\
\hline $\mathrm{LV}$ & $\begin{array}{l}\text { Low Vision. An incurable visual impairment which cannot be sufficiently improved with optical } \\
\text { correction and which interferes with activities. }{ }^{4-6}\end{array}$ \\
\hline LVR & $\begin{array}{l}\text { Low vision rehabilitation (low vision services, low vision intervention, low vision care) } \\
\text { includes low vision assessment and may include the provision of low vision assistive devices, } \\
\text { environmental/lifestyle modifications, education, training and alternative techniques. }\end{array}$ \\
\hline PRL & $\begin{array}{l}\text { Preferred retinal locus. One or more regions of functioning retina consistently used for fixation } \\
\text { instead of the fovea in an individual with bilateral dense central scotomas. The PRL may be used } \\
\text { for attentional deployment and as the oculomotor reference. }\end{array}$ \\
\hline VA & Visual acuity \\
\hline $\begin{array}{l}\text { Handicap or participation } \\
\text { restriction }\end{array}$ & $\begin{array}{l}\text { A limitation in involvement in life, a psychosocial disadvantage that occurs because of the } \\
\text { disability } 5,8\end{array}$ \\
\hline Visual disorder & $\begin{array}{l}\text { Any deviation from the normal structure or function of the eye or visual system due to disease, } \\
\text { trauma or congenital anomaly } y^{5,8}\end{array}$ \\
\hline $\begin{array}{l}\text { Visual disability/activity } \\
\text { limitation }\end{array}$ & $\begin{array}{l}\text { A reduced ability to perform a desired task (for that individual) because of the visual } \\
\text { impairment } t^{5,8}\end{array}$ \\
\hline Visual impairment & $\begin{array}{l}\text { A measurable chronic reduction of vision compared to the normal age-related values. It is } \\
\text { assumed that all optical, surgical or medical treatment has been undertaken or considered }{ }^{5,8}\end{array}$ \\
\hline
\end{tabular}




\subsubsection{LOW VISION}

The World Health Organization (WHO) provided a classification system to address the consequences of disease. They proposed that disease causes an impairment in structure or function. This, in turn, creates a disability/activity limitation wherein the individual is unable to complete a particular task in the usual manner, as a result of the impact of the impairment. A handicap/participation restriction occurs when the individual's interaction with their environment is affected as a result of the disability. ${ }^{8}$

For clinical purposes the determination of low vision is ideally determined by the presence of incurable disease that impairs visual function. However, research and legal definitions often define low vision on the degree of visual acuity impairment. The WHO considers an individual as having low vision when best corrected visual acuity (VA) is poorer than 6/18 (20/60) to 6/120 (20/400). A person with VA poorer than 6/120 or with a visual field of less than 10 degrees is considered legally blind. ${ }^{9}$ The North American classification defines legal blindness as 6/60 or poorer, or a visual field of 20 degrees or less, and recognizes that low vision occurs with less severe acuity impairment, defining low vision as worse than 6/12 (<20/40). ${ }^{10}$ This level is identified by other authors as a level at which disability typically begins. ${ }^{4,5,11}$ In Canada, definitions for eligibility for services and assistive plans are typically based on specific levels of visual acuity or visual field loss (See Appendix A for details regarding eligibility for low vision rehabilitation and devices according to province).

This guideline adopts a functional or disability-based definition of low vision, which is patient-centred, and seeks to account for the full scope of a patient's visual impairment and their individual disabilities. Low vision is defined as occurring when a visual impairment results in a person not being able to perform his or her desired visual tasks. It is based on the best monocular or binocular performance which is expected to be long-standing. Typically, low vision is either due to loss of visual acuity, visual fields or contrast sensitivity, or a combination of these. ${ }^{4,5}$ For visual field impairment loss, disability starts when the visual fields is $<70^{\circ}$ circular diameter or equivalent. ${ }^{12}$ For contrast sensitivity, a disability starts when performance on a letter test of contrast sensitivity drops to Log CS of $<1.40 .{ }^{13-15}$ Nevertheless, neither of these criteria are strict cut-offs; they are intended as general indications only.

\subsubsection{LOW VISION REHABILITATION}

Low vision rehabilitation (LVR) includes visual assessment specific to visual impairment and may include the provision of low vision assistive devices, environmental/lifestyle modifications, education, training and alternative techniques. The purpose of LVR is to help the individual with low vision to achieve their personal visual goals, attain maximum function, achieve their desired level of independence, and attain a safe and satisfying lifestyle. Synonyms include low vision services, low vision intervention, and low vision care.

\subsection{EPIDEMIOLOGY}

To date, there is no comprehensive population based study of low vision prevalence in Canada. The studies which do exist include correctable forms of impairment such as refractive error and/or cataract. Using a definition which includes individuals with cataracts, Maberley et al. provided useful national prevalence data based on extrapolations from clinical records of best-corrected acuity and visual field status for the better-seeing eye in a medium sized Canadian city. They estimated that $0.39 \%$ of the total population has visual impairment (including low vision and blindness) according to the WHO classification $(<6 / 21[<20 / 70])$ which increased to $0.95 \%$ utilizing the North American definition $(<6 / 12[<20 / 40])$. Using the latter definition, the prevalence rises to $8.9 \%$ of people aged $75-84$ years and $18 \%$ of those aged $85+.{ }^{10}$ These estimates include about $30 \%$ of all patients having impaired vision due to cataract or complications of cataract as the primary etiology, suggesting possible over-estimation. A more recent study reported that $5.7 \%$ of Canadian adults aged $45-84$ years have some form of reduced vision. This percentage increased from $2.7 \%$ in $45-54$ year olds to $15.6 \%$ in $75-84$ year olds. ${ }^{16}$ Notably, uncorrected refractive error was thought to be the cause of reduced vision for $64-80 \%$ of participants, while self-reported cataract was present for $5.6 \%{ }^{16}$

More comprehensive population studies have been conducted in other developed countries. The studies focused on middle aged and older adults, and most used a definition of best-corrected VA of 6/12 (20/40) or worse. These include the Beaver Dam study (5.9\%), ${ }^{17}$ the Salisbury Eye Evaluation study (3.7\%), ${ }^{18}$ and the Blue Mountain study (4.7\%). ${ }^{19}$ These studies all demonstrated an increased prevalence of visual impairment with age. Chan et al. showed that visual impairment rises exponentially with age. ${ }^{20}$ They modelled the prevalence of visual impairment in the US over the next 30 years and predicted a similar prevalence for best corrected VA worse than $6 / 12$ of $3.9 \%$ for $\geq 45$ year olds, resulting in a doubling of the number of people with visual impairment in that time. This age dependence is a concern, as the Canadian population is aging, with expectations that approximately $23-25 \%$ of the population will 
be comprised of older adults by $2036 .{ }^{21}$ The rise in diabetes rates with age, and the associated visual impairment due to diabetic retinopathy, is an additional concern. Between the ages of 75 and $79,23.1 \%$ women and $28.5 \%$ men have diabetes. ${ }^{22}$ The rise in total numbers of new cases of visual impairment indicates a substantial increase in the need for low vision rehabilitation services over the next 30 years. ${ }^{20}$

The distribution of severity of visual impairment among individuals is relevant in anticipating the scope of disability and the corresponding demand for rehabilitation. A large portion of the visually impaired population have mild or moderate visual impairment. In the population study by Attebo et al., $72 \%$ of older adults with visual impairment had mild visual impairment $(6 / 12 \text { to } 6 / 18)^{19}$ while Chan et al. reported that $60 \%$ of cases were mild LV, $23 \%$ were moderate $(<6 / 18$ to better than $6 / 60)$ and $17 \%$ were $\leq 6 / 60 .{ }^{20}$ Goldstein et al. reported that $37 \%$ of patients served by outpatient low vision services had mild LV (VA equal or better than 6/18 [20/60]) while a further $38 \%$ had moderate visual impairment $(6 / 18-<6 / 60[20 / 60-<20 / 200]) .{ }^{23}$ Contrast sensitivity deficits were classified as mild in $24 \%$ and moderate in $43 \%$. This predominance of mild visual impairment would be consistent with the expectation that the needs of most individuals with impaired vision could be met with more modest interventions, such as a thorough optometric low vision rehabilitation rather than requiring more comprehensive, multidisciplinary approaches. ${ }^{24}$

\subsection{IMPACT OF VISUAL IMPAIRMENT}

The impact of visual impairment can be substantial. With the progression of the disease, and subsequent impairment, there is an associated increased difficulty with visually intensive tasks such as reading and mobility. ${ }^{15}$ There are also deficiencies in performance of daily living tasks, such as personal care, shopping and meal preparation. This is true compared to the general population, as well as compared to those living with other chronic conditions. ${ }^{25} \mathrm{Often}$, those with suboptimal vision will fail to meet the vision driving standard resulting in loss of their driver's license. This further exacerbates other negative effects of impairment, such as social isolation, as driving is typically the desired method of transportation. ${ }^{26}$ People with visual impairment are more likely to discontinue their education or take longer to achieve their educational goals. ${ }^{27}$ Only $35-45 \%$ of visually impaired people are employed, ${ }^{27-29}$ and this is lower still for women (only $24.5 \%$ being employed), younger people and those with diabetes. Those with visual impairment are more likely to experience multiple falls. ${ }^{30,31}$ For visual acuity $<20 / 30$ the prevalence ratio is 1.9 and for 5 or more missing points on the visual field the prevalence ratio is $1.5{ }^{32}$ These factors and others contribute to an overall decrease in quality of life, and negatively affect mental health, leading to higher levels of depression. ${ }^{33}$ People with visual impairment due to diabetes are especially at risk for difficulty adjusting to vision loss. ${ }^{33}$ Older adults with visual impairment are $2 \mathrm{x}$ more likely to have depression and have difficulty with emotional adjustment and isolation. ${ }^{34}$ It is noteworthy that there is no clear association between the level of visual impairment and the severity of depression, ${ }^{35}$ although better adjustment to vision loss is documented for people with better VA. ${ }^{33}$ There are increased rates of suicide and mortality among people with visual impairment; even mild visual impairment increases mortality by more than 2 times. ${ }^{36-38}$

\subsection{THE NEED FOR LOW VISION REHABILITATION AND THE ROLE OF OPTOMETRISTS}

Despite the documented effectiveness of LVR (see Appendix B), many people with low vision are not accessing low vision rehabilitation services. This is either because they are not referred, are not aware of such services, or because there are barriers that dissuade them from attending: ${ }^{39}$ In Quebec, $75 \%$ of community-dwelling people aged 65 years+ with visual impairment had not utilised low vision services ${ }^{40}$ while $67 \%$ of ophthalmology clinic patients with low vision had not heard of, or been referred to, LVR. ${ }^{41}$ In Ontario, $74 \%$ of community dwelling adults were unaware of low vision services ${ }^{42}$ and $50 \%$ of hospital patients with low vision were not referred for LVR. ${ }^{43}$ Those less likely to be referred include those with visual disorders other than age-related macular degeneration, less education, more recent vision loss, and reduced VA that doesn't meet legal blindness requirements. Those who live alone and certain ethnic groups such as African Canadians are also less likely to be referred. ${ }^{41}$ As primary vision care providers, all optometrists have a vital role to play in identifying patients who could benefit from LVR and ensuring that patients who require LVR are informed about low vision rehabilitation services. Optometrists may choose to provide that service themselves or refer accordingly. It is known that low vision rehabilitation is often more effective when provided at the early stages of visual impairment. It is important to address visual disabilities early, so that the patient does not experience unnecessary years of disability and participation restriction. Therefore, referral for, or provision of, LVR should be as soon as the patient experiences permanent low vision. LVR should be a parallel process to treatment when it is known that vision loss is irreversible.

\subsection{THE EFFECTIVENESS OF LOW VISION REHABILITATION}

Appendix B summarises systematic reviews regarding the effectiveness of various low vision rehabilitation interventions. According to the systematic review of Binns et al. there is good evidence that low vision rehabilitation, as a whole, is effective. Over the years, the question has been approached using different outcomes and study designs. 
Cohort studies have provided very good evidence of the effectiveness of low vision rehabilitation as demonstrated by: improvements in clinical measures of ability to read smaller print, reading speed or reading duration with magnification devices; ${ }^{44-46}$ the value that patients place on their devices and their continued use of devices (reported between 67-99\%); patients' reported satisfaction with low vision services (between 83 and 98\%); ${ }^{4-50}$ patients' selfreported functional ability ${ }^{46}$ and improved quality of life. ${ }^{51-56}$

Randomised clinical trials give a stronger level of evidence and have also indicated that low vision services are effective. One of the most comprehensive studies to date is the LOVIT randomised clinical trial which showed that full multidisciplinary LVR as offered by the U.S. Department of Veterans Affairs is effective compared to delayed intervention. ${ }^{57}$ There were significant improvements in all areas of visual function for the treatment group. Significant benefit has also been shown for a broader demographic of patients attending out-patient low vision clinics, although with a smaller effect size. ${ }^{58}$

\subsubsection{LOW VISION REHABILITATION PROVIDED BY OPTOMETRISTS}

Low vision rehabilitation, primarily provided by optometrists in the community, has also been shown to be effective. ${ }^{59}$ Patients valued the optometric low vision service which they received in university-based or communitybased low vision clinics and continued to use their assistive devices. ${ }^{49,50,60}$ The improvements in quality of life were similar between individuals experiencing optometric low vision rehabilitation and multidisciplinary services. ${ }^{55}$ The recent LOVIT II study (a randomised clinical trial) showed no differences in visual function outcomes between basic and fully comprehensive services for people with relatively mild visual impairment (in the range of VA $6 / 15$ to $6 / 18[20 / 50$ to $20 / 60]) .^{24}$

\subsection{MODELS OF LOW VISION REHABILITATION}

Since the early $20^{\text {th }}$ century, a variety of models of low vision care provision have developed including in-patient, out-patient, hospital-based, community-based, individual and group programs. ${ }^{46,61}$ In Scandinavia ${ }^{62}$ and Australia ${ }^{63}$ the concept of multidisciplinary/interdisciplinary clinics that included vision therapists was developed. A full multidisciplinary team may include optometrists, ophthalmologists, opticians, social workers, low vision therapists, high technology assessors, counsellors, orientation and mobility specialists and occupational therapists. These clinics were centred in the community and were shown to provide beneficial results. Despite little evidence regarding the relative effectiveness of different models, ${ }^{55,58,64,65}$ the multidisciplinary/interdisciplinary model of comprehensive low vision rehabilitation has become generally accepted as the "gold standard" for people with more severe visual impairment and more complex needs. ${ }^{61,66-70}$

It is recognized, however, that not all people with visual impairment require full multidisciplinary intervention. The WHO reported that approximately $80 \%$ of people with less severe levels of low vision can benefit from intervention at a basic level. ${ }^{61,66}$ Therefore, the WHO recommends a three tier model of low vision provision. ${ }^{61,66}$ In Wales, this concept was shown to be effective ${ }^{48}$, with local optometrists providing initial services and linking with other local community-based professionals and voluntary organisations to provide some level of multidisciplinary support when necessary. ${ }^{50}$ This service model improved accessibility to low vision rehabilitation resulting in more people receiving LV services and decreased waiting times and travel distances for patients. A similar model with optometrists providing initial, basic low vision rehabilitation has been suggested for Canada ${ }^{71}$ and Australia $^{72}$, both large geographic areas with sparse populations in many regions. For equitable patient access to rehabilitation, optometrists are ideally qualified ${ }^{73}$ and situated to be key players in basic low vision provision. They are also instrumental in full multidisciplinary/interdisciplinary settings, providing the initial assessment and interventions, plus devising a rehabilitation plan. ${ }^{74}$ The model proposed for Canada is a three tiered model ${ }^{71}$. It is described in Appendix $\mathrm{C}$ and includes the following levels:

1. Screening and recognition of a potential patient with low vision followed by appropriate triage,

2. LVR of a patient with mild visual impairment/disability,

3. Comprehensive LVR for patients with more severe visual impairment and greater disabilities whose rehabilitation requires collaboration with other professionals.

Such a model, with two levels of LVR, has been adopted in Ontario by the Eye Health Council of Ontario.$^{75}$ This Clinical Practice Guideline is intended to assist optometrists who provide LVR at Levels 2 or 3. 


\section{OPTOMETRIC LOW VISION REHABILITATION}

LVR includes Low Vision Assessment and Low Vision Management. It starts with a full low vision assessment which is an extended evaluation of visual function and a review of ocular disease and systemic health conditions that may impact visual function and functional vision. Visual function is the measured capability of the visual system and functional vision relates to the ability of the person to undertake vision-related tasks. ${ }^{76}$ The low vision assessment results in the creation of an initial Low Vision Rehabilitation plan for low vision management. Low Vision Rehabilitation management includes the assessment for, and training with, various optical and/or non-optical low vision aids and/ or rehabilitation strategies directed towards the patient's specific needs, as well as supportive patient education and counselling. The result is the final rehabilitation plan, which is the final recommendations for the patient.

\subsection{LOW VISION REHABILITATION - ASSESSMENT}

\subsubsection{CASE HISTORY}

The low vision assessment starts with a comprehensive case history. The comprehensive case history should be targeted towards the patient's self-reported disabilities and goals, but should also review the functional domains which might be impacted by the visual impairment, including activities of daily living, social activities, recreational activities and vocational/educational requirements. ${ }^{77}$ It may be useful to ask the patient to describe their typical day and then ask how they manage each task. For a complete Activity Inventory of tasks and subtasks see Massof. ${ }^{78}$

Because of the typical variety and number of goals, it may not be possible to address all in one session, so prioritizing the goals with the patient is often helpful at this stage. Other important components of the case history are an evaluation of the effectiveness of current spectacles, low vision devices, and other adaptive strategies for a range of tasks. Discussing the effects of glare and lighting on their daily activities is also helpful.

Ocular, general health and family history and current medications should be reviewed, including the stability of the ocular condition and any current or future treatments. Additionally, the case history should explore the patient's understanding and perception of his/her eye condition and its impact on functional vision and the likelihood of progression. It is also important to determine any recent history of falls.

The patient's social history should be discussed, including living arrangements, mobility and use of support and community services. The optometrist should be cognisant of the likelihood of depression among people with low vision, and a depression screener such as the PHQ-2 can be administered (Table 2). For a child patient it is important to determine what school support services are in place.

Some additional information may be gathered from reports and referrals. The use of an intake questionnaire is useful to gather most of this information in advance and can help the patient identify their primary difficulties and goals.

For a list of case history components, refer to the American Optometric Association Guideline, Care of the Patient with Visual Impairment, Appendix Table $3 .^{68}$

Table 2: $P H Q-2^{79}$

\begin{tabular}{|l|c|c|c|c|c|}
\hline $\begin{array}{l}\text { During the last } 2 \text { weeks, how often have } \\
\text { you been bothered by the following? }\end{array}$ & Not at all & Several days & $\begin{array}{c}\text { More than half } \\
\text { the days }\end{array}$ & $\begin{array}{c}\text { Nearly every } \\
\text { day }\end{array}$ & $\begin{array}{c}\text { Score for } \\
\text { question }\end{array}$ \\
\hline Little interest or pleasure in doing things & 0 & 1 & 2 & 3 & \\
\hline 2. Feeling down, depressed or hopeless & 0 & 1 & 2 & 3 & \\
\hline $\begin{array}{l}\text { Total score (a score of } 3 \text { or more is } \\
\text { positive for depression) }\end{array}$ & & & & & \\
\hline
\end{tabular}

\subsubsection{VISUAL ACUITY}

Distance visual acuity: The assessment usually continues with the measurement of entering distance VA. Printed charts are recommended for patients with low vision, as testing distances can be easily varied depending on acuity level and the illumination can be changed without changing the contrast. Charts based on a logMAR design such as the Early Treatment Diabetic Retinopathy Study (ETDRS) and Bailey-Lovie charts are preferred, because they have equal numbers of letters per line (usually five), equivalent spacing between 
letters and lines to control crowding, and follow a logarithmic progression. This means that visual acuity measurements are consistent with different testing distances. ${ }^{80-82}$ The use of multiple letters per row gives useful information regarding scotoma position, eccentric viewing, fixation stability and eye movement control. Other charts, such as the Feinbloom, Feinbloom PV numbers, or Lea numbers are useful as they are more portable and enable the measurement of very low levels of acuity. However, they are not designed in a fully logarithmic progression for letter size and spacing and do not have equal numbers of numbers per line over the whole chart. ${ }^{83}$ For patients with very low visual acuity, the Berkeley Rudimentary Vision Test quantifies VA as low as 6/4800 (20/16,000). ${ }^{84}$ Electronic versions of VA charts are also available, for example, the Freiburg Acuity Test, which can also measure VA to low levels. ${ }^{85}$ Computerised charts are likely to become more widely used, and will allow more diversity of variables such as optotype, spatial arrangement and contrast, but careful documentation is important for standardisation and comparison. ${ }^{86}$

For children, charts using the Lea or Patti Pics symbols are available in a variety of formats in a logarithmic scale. Preferential looking with Teller cards or Cardiff cards can be used to measure VA for infants or patients with developmental delays. Visually evoked potentials can be used for those who cannot respond to any of these tests. Care must be taken in the interpretation of VA measured either with preferential looking or visually evoked potentials, since these measure resolution VA which is not equivalent to VA measured with letters or shapes. ${ }^{87,88}$

When recording VA it is important to document the actual testing distance and M letters read, the chart used, and the use of any modifications (e.g., lighting levels). It is also important to observe the patient and record the use of eccentric fixation or adopted postures, together with any patterns of missed or incorrect letters.

Near visual acuity: Charts include single letter (reduced Snellen), unrelated word and continuous text charts. Single letter charts may be used for a quick estimate and for children or adults with limited literacy. Continuous text charts give a better understanding of performance in reading and reading related tasks. Continuous text charts include the MNREAD (available in many languages), the New Lighthouse, the Lighthouse chart for children, the Colenbrander charts (also available in many languages), the Radner charts, the Balsam Alabdulkader-Leat (BAL) charts in Arabic and the C-Read charts in Chinese. The MNREAD charts are also available on an iPad and have been shown to give equivalent results to the printed version. ${ }^{89}$ All these will give a satisfactorily repeatable and valid measure of near VA in M print or logMAR for the calculation of magnification.

Continuous text reading cards allow measurement of maximum reading speed, critical print size and reading acuity. These measures are useful for determining prognosis for meaningful reading and for calculating the magnification levels required for various tasks. Reading acuity is often evaluated with each eye separately, as the eye which has previously been the patient's "better eye" may not always give the best reading fluency. Some patients may perform better for reading with one eye occluded, and this can be evaluated at this point in the assessment. Binocular reading performance should also be assessed, to determine any inter-ocular interference or enhancement. The SK Read Chart is designed on the logMAR principle and is composed of unrelated words and letters. It is designed to give additional information regarding the types of errors that are made due to central or paracentral field loss and can be used for training. The IResT charts are designed to measure reading speed for standardised paragraphs of text in a single print size, and are also available in multiple languages.

Lighting can have a substantial impact on both distance and near VA for people with low vision, so the effect of illumination on VA can be considered by increasing or decreasing the illuminance. ${ }^{1}$ The optimal lighting level is dependent on the ocular disorder. ${ }^{90,91}$

\subsubsection{REFRACTION}

Objective and subjective refraction are fundamental components of a low vision assessment and spectacle correction should be optimized before pursuing additional devices. Often a significant VA improvement can be gained (11$16 \%$ of patients can gain a moderate to large improvement with refraction ${ }^{44,92}$ ) and it is important for the assessment and dispensing of most optical devices that the correct refraction be in place. Note that the pinhole is rarely useful to determine refractive change in patients with low vision because of the reduced illumination or presence of a central scotoma and need for eccentric fixation, and so an actual refraction is necessary.

Objective refraction with retinoscopy can be conducted as usual, although when the reflex is dim or less clear, alternative techniques should be explored. These include radical retinoscopy (closer working distance than usual), 
bracketing neutral, off-axis retinoscopy, working in very low light levels, trialing high powered lenses and near (Mohindra) retinoscopy. Autorefractors can give an objective result when the media are relatively clear.

Subjective refraction is ideally undertaken in a trial frame because phoropter refraction may be limited due to factors such as the presence of central or peripheral scotomas and the need to make larger lens changes. Monocular refraction is typically employed, and non-standard distances can be used to allow the patient to see a line of letters. Correction to infinity can be applied afterwards.

Lens changes should be based on the concept of a just noticeable difference (JND), either determined by the guideline (denominator of the 20 foot Snellen fraction in feet/100) or by patient trial (starting with a large lens change, and reducing it based on the patient's ability to detect a change). For spherical refraction in presbyopes, the bracketing method is efficient. In pre-presbyopes, vision should first be fogged to relax accommodation by the addition of positive lenses, followed by progressive addition of minus (less plus). The highest plus (or lowest minus) lens of a pair of lenses which results in a "no difference" response is the correct sphere. Crossed-cyl technique can be used in both presbyopes and pre-presbyopes using higher powers of cross-cylinder lenses. Cycloplegic refraction is not contraindicated in most young low vision patients.

\subsubsection{OCULAR ALIGNMENT AND MOTILITY}

It is important to determine the ocular alignment of the patient, as it is relevant information for choosing binocular versus monocular devices. The Hirschberg test can be employed (although eccentric viewing may affect the apparent fixing eye). A cover test can also be employed with a suitably large target.

For patients with nystagmus, evaluation of the null point should be assessed during a motility test. This is best undertaken by pausing the target at different positions as the nystagmus may dampen with a stationery target.

\subsubsection{CONTRAST SENSITIVITY (CS)}

CS testing gives valuable information regarding the potential for reading and is predictive of difficulty with a wide range of other visual tasks (daily living skills, mobility, face discrimination, driving) and perceived disability. 14,15,93-101 CS may explain a patient's difficulty when VA is relatively preserved. Poor CS is also a risk factor for falls..$^{102,103}$ Often low vision patients have not previously had their contrast sensitivity measured. As a result, an important role for the low vision optometrist is to perform CS testing and to educate patients and their circle of care on the implications of any contrast sensitivity deficits.

Consequently, CS charts should be available to the LV clinician. Recommended and validated CS charts are the Pelli-Robson Contrast Sensitivity and Mars Letter Contrast Sensitivity charts. The measurements on these are interchangeable. ${ }^{104}$ Other options are the Sloan Letter Low Contrast flip chart or the Rabin Contrast sensitivity chart. The Patti Pics or Lea symbols are available for young children. Low contrast acuity charts are available, but these do not give the same predictive information as CS charts, and have been less intensively studied. As the name implies, they give a visual acuity measurement for a target at a specific low level of contrast (e.g., $10 \%$ ), and are thus not interchangeable with true CS charts in which the contrast changes to determine the threshold. Low contrast acuity charts may be useful for demonstrating to a patient the effects of contrast on their vision, i.e., how much their VA decreases with a reduction of contrast). There are mixed contrast charts for distance and near VA testing.

\subsubsection{VISUAL FIELDS}

Depending on the ocular diagnosis and the expected field loss, the LV clinician may measure central or peripheral fields.

Measurement of central visual field loss is the first step of eccentric viewing training. Central field loss can be estimated with the Amsler grid, although a negative result is not reliable. ${ }^{105}$ Amsler grid at low light levels (e.g., with the NoIR 4\% grey) can show field defects more reliably. ${ }^{106}$ The tangent screen and its modifications (modified Amsler, California Central Visual Field test) can give useful information about central scotomas. The Humphrey can also be used, but threshold testing will be time consuming in LV patients. Microperimetry is the most accurate way of measuring central fields when there is a central scotoma.

Peripheral field loss can be documented with kinetic perimetry such as the Goldmann, or with static perimetry such as the Humphrey Field Analyser or the Octopus. 


\subsubsection{COLOUR VISION}

Although colour vision testing is less critical than impairment of VA, CS or fields, many patients with visual impairment will have colour vision defects. Being able to measure colour vision and discuss it with patients is important. Blue-yellow defects are common in addition to red-green, so a test that can identify both types of defect is required. Pseudo-isochromatic plates may be of contrast that is too low and therefore maybe too sensitive for patients with low vision. A good test is the Farnsworth D15 (enlarged D15 for patients with lower levels of VA). Allowing the patient to bring the chips closer is acceptable.

\subsubsection{GLARE TESTING}

Many LV patients have glare difficulties. Although it is usually acceptable to rely on the patient's symptoms and undertake a tint assessment, glare testing may be useful in some cases (e.g., in documenting glare disability in a patient considered for cataract surgery). The Brightness Acuity Test is the clinical standard but an estimate can be obtained by measuring VA or CS in the presence of a glare source in proximity to the chart or with a transilluminator or penlight held close to the patient at an angle to his/her line of sight.

\subsubsection{OCULAR HEALTH ASSESSMENT}

Evaluating the ocular health of low vision patients is useful for relating structure to function of low vision patients. It allows clinicians to evaluate the state of the eye disease causing the visual impairment, and any progression from a previous assessment. For patients with more than one ocular disease contributing to visual impairment, examining the health and state of patients' eyes gives the clinician a better understanding of how each condition is affecting vision. The components of ocular health assessment may include:

- Anterior eye examination by slit-lamp biomicroscopy

- Tonometry

- Interior ocular examination by non-dilated fundus evaluation if possible

\subsubsection{ADDITIONAL ASSESSMENTS}

\section{Ocular health assessment by dilated fundus examination}

Dilated examination of the interior ocular structures is not routinely included in a LV assessment, as this is commonly undertaken in a separate, prior oculo-visual assessment or by the patient's primary care optometrist or ophthalmologist. However, there are occasions where the presenting symptoms, disabilities or measurements do not accord with the patient's diagnosis or when there is no recent ocular health assessment. In these circumstances, the LV clinician may have to postpone the low vision assessment in favour of an assessment of ocular health or arrange for a subsequent appointment for an ocular health assessment. The low vision assessment cannot proceed after dilation, as most measurements will be affected.

\section{Imaging (e.g., Optical Coherence Tomography, ultrasound)}

Electrodiagnostic testing: ERG, VEP or EOG may be necessary to confirm or establish a diagnosis, rule out disease or obtain a measure of visual acuity in some cases.

\subsubsection{CREATION OF THE INITIAL REHABILITATION PLAN}

At the conclusion of the assessment, the LV optometrist is able to create an initial Low Vision Rehabilitation Plan, which may include any or all of the components described below. The plan should be disseminated in any reports that are made available so that all professionals are made aware of the findings and plan. Many components can be implemented by the low vision optometrist, together with an in-office low vision assistant or therapist. Implementation of the full plan may require referral to other service providers.

\subsection{LOW VISION REHABILITATION - MANAGEMENT}

The tools at the disposal of the LV clinician include optical, non-optical and electronic magnification, increased contrast, lighting control, minification, relocation of the object or image, training, and adaptations. Patient and family education and referrals to other service providers are also important components. As yet, there is little high level evidence that one specific type of evidence or approach is more effective than others (Appendix B) although, as described earlier, it is known that LVR as a whole is effective. Therefore, the fol- 
lowing discussion relies on expert opinion and other research evidence that is available. Broad approaches are described, although ultimately what is effective for each patient should be recommended and prescribed.

\subsubsection{MANAGEMENT OF CENTRAL VISION LOSS}

The majority of patients presenting in low vision settings have some level of visual acuity reduction and will benefit from magnification for near and distance tasks. The most frequent goal of patients is reading and other detailed tasks such as sewing, writing, and watching TV.

\section{Near Magnification}

Magnification requirements may differ depending on the task required by the patient. There are several ways to estimate starting magnification for near, and these are reviewed in Appendix D. Most of these methods take into account the patient's task requirements in terms of a target print size. Note that these estimates are starting points for the magnification or equivalent viewing power (EVP)/near add required and that higher, and sometimes lower, magnifications should be trialed.

\section{Optical devices for near magnification}

Spectacle mounted reading lenses/high adds/microscopes: These devices are spectacle-mounted plus lenses consisting of a near addition (plus power) to allow close focus to produce relative distance magnification. Some examples include single vision readers, bifocal near additions, prism half-eyes or clip-on lens. The power is determined as described in Appendix D. These can be demonstrated in a trial frame, with ready-made prism half-eyes or microscopes. Custom reading glasses or microscopes address the needs of those with significant anisometropia or astigmatism, and may provide superior optical quality. Head-band, clip-on and bar-mounted microscopes are available for tasks which require a greater working distance, which is obtained because the lens to eye distance is increased.

In an absolute presbyope, the patient's working distance in using the device should be the focal length of the near addition. If the patient has accommodation, it would supplement the power of the add. The working distance would then be closer than the focal length of the device. The method for estimating the reading addition in pre-presbyopes is described in Appendix D. Microscopes can be prescribed binocularly up to a $+12 \mathrm{D}$, or even $14 \mathrm{D}$, add, but decentration and base in prisms must be considered with higher adds due to the near working distance and demand on convergence (see Appendix E).

Hand magnifiers (HM): These devices comprise a plus lens mounted on a handle that the patient holds at a distance away from the object. They are often prescribed for brief reading tasks and can range in magnification, size and illumination. A certain amount of dexterity is required of the patient as the distance between the magnifier and object must be maintained to view properly.

HMs can be trialed with power equal to the EVP calculated for a microscope. When the patient views through the distance portion of the spectacles while using the magnifier, the EVP obtained equals the power of the hand magnifier irrespective of distance, and the print or object being viewed should be held at the focal length of the magnifier. However, when the patient views through their reading addition while using the magnifier, the total EVP is dependent on the distance that the HM is held. The EVP obtained is less than the power of the magnifier when the HM is held further than the focal length of the hand magnifier. Thus, when the patient holds the HM further than its focal length, the patient should view through the distance portion of spectacles to gain maximum EVP. When it is held closer than the focal length of the HM lens, the patient can either view through the distance or reading portion of their spectacles. In all cases, the field of view increases as the distance between the magnifier and eye decreases.

Stand Magnifiers (SM): A stand magnifier is comprised of a positive lens mounted in a stand that sits on the object (usually the page). Dome magnifiers are classified as stand magnifiers - the thickness of the glass acts as the "stand". Stand magnifiers may benefit patients with dexterity issues, as the distance between the magnifier and object is fixed. They can be advantageous compared to hand magnifiers when a higher lens power is required and when steadiness and lens positioning become more critical. They are available with or without internal illumination. The preliminary testing with different light levels will indicate which type is likely to be beneficial. The light exiting a stand magnifier is divergent to a greater or lesser extent, creating a virtual image that is closer than infinity. This means that either accommodation or a reading addition is required to obtain a clear image, and the low vision op- 
tometrist needs to be aware of the emergent vergence (image position) for each stand magnifier in his/her inventory (Appendix F). Stand magnifiers can be trialed with a transverse magnification (TM, sometimes called enlargement ratio) equal to the estimated magnification (Appendix D). The transverse magnification is not equal to the magnification marked on the device (nominal or trade magnification), but it is often available in the manufacturer's technical specifications and can also be calculated in advance by the LV optometrist. Similarly, the emergent vergence can be measured or found in suppliers' or manufacturers' catalogues or technical specifications.

Telemicroscopes: A telemicroscope is an afocal telescope focused for close work by a positive lens placed on the objective lens. These can give magnification for either near or intermediate tasks. They tend to be used for more specialized hands-free tasks, which require longer working distances. They can be prescribed in terms of magnification (if the patient's acuity is measured at the task working distance) or equivalent viewing power. Formulae are provided in Appendix F.

Often an example of each type of device will be trialed. The final type of device should be considered in terms of the patient's preference and ease of use, binocular versus monocular performance, hands free needs and lighting requirements. The magnification or EVP should be increased (and in some cases decreased) to obtain the optimum performance in terms of reading fluency or task performance, endurance, and acuity through the device. Higher magnification may provide better fluency at the patient's goal print size, ${ }^{1}$ while lower magnification may be sufficient and be easier to use.

Contact lenses: Contact lenses can be considered for high myopes, as they will lose some spectacle minification. Possible undercorrection with a spectacle lens over-correction may be beneficial, so that the patient can still benefit from the relative distance magnification gained by removing their spectacles.

\section{When optical magnification is insufficient for the task}

Reading (and writing) are complex tasks. There are occasions when a patient is unable to read their goal print fluently despite trialing a range of devices and magnifications. The most common causes for this are:

- a very large and dense central scotoma (requiring a preferred retinal locus [PRL]) that is far from the anatomical fovea

- very poor visual acuity, such that a sufficient acuity reserve cannot be obtained

- poor contrast sensitivity

- restricted visual fields, such that there are insufficient characters within the visual field

- paracentral scotomas located in positions within the visual field that are critical for reading.

There are indications that an acuity reserve less than $2 \mathrm{x}$, contrast sensitivity which is $<1.00$, a PRL which is $>15^{\circ}$ away from the anatomical fovea or a field of view that is $<5$ characters across will severely restrict reading rates. ${ }^{1,94-96}$ In these cases, electronic magnification, eccentric viewing training, and/or non-optical solutions should be explored. However, optical magnification may still be useful for certain brief reading tasks.

Electronic magnification and accessibility options: Electronic magnification and accessibility options should also be considered for many patients. This may include a discussion of the accessibility options which are now available on current devices (mobile phone, tablet, laptop). Accessible features include text to speech, voice assist, talk-back and magnification, contrast, font and colour options. Adapted computers (software and hardware adaptations) can be demonstrated, or an assessment can be recommended.

A demonstration or assessment for video magnification, such as hand-held, portable and desktop video magnifiers (CCTVs), is often indicated. Video-magnification is particularly useful when a patient has poor contrast sensitivity (because of the contrast enhancement options). Portable video magnifiers may be a useful supplemental device for patients who also have optical devices and perform well with them. They can be considered for similar tasks as a stand magnifier. Optical aids may be used more frequently and for more tasks, while hand-held video-magnifiers may allow reading of smaller print and be preferred for leisure reading. ${ }^{107,108}$ Because of their variable magnifica- 
tion, hand-held video-magnifiers may be a cost effective solution. ${ }^{109}$ For more prolonged tasks, the functionality of a portable video magnifier should be compared against a desk-top video magnifier. Desk-top video magnifiers are also useful when patients require higher levels of magnification, variable magnification due to disease progression, or assistance for writing and extended reading, or have constricted or hemianopic visual fields. Reading speeds may be higher with the use of CCTV devices compared to optical magnification even with eccentric viewing training. ${ }^{110}$

\section{Writing}

People with central vision loss may also require magnification for writing. Typically, less magnification is required for writing compared to reading. Often, a target of $2 \mathrm{M}$ may suffice, which frequently means about half the magnification compared to reading. Thus spectacle-mounted devices may be an option for writing even if they are not suitable for reading. There are optical and electronic stand magnifiers with a gap in the stand on one side, which allow for the use of a pen. Clip-on, bar mounted, or head-band magnifiers may also be options for this activity. Video magnifiers (desk-top types and hand-held or portable CCTVs mounted in a stand) and adapted computers may be considered as writing devices.

\section{Distance magnification}

Although the management methods for distance are more limited in scope than the variety provided for near work, there are still a number that can be applied to increase the quality of life. Telescopes are the main method of providing magnification for distance tasks (although in some cases relative distance magnification can be achieved, e.g., decreasing the viewing distance for TV).

\section{Optical devices for distance magnification}

Telescopic magnifiers: Telescopic magnifiers can be categorised as Galilean or Keplerian, handheld versus spectacle mounted, monocular versus binocular, and ready-made or custom. The choice is based on the magnification required, and the goals and abilities of the patient.

Galilean telescopes have the advantage of being lighter and less expensive than Keplerian telescopes, but are limited to $\leq 4 \mathrm{x}$ magnification. Therefore, they serve best for patients with minimum magnification requirements. Keplerian telescopes, sometimes called prism telescopes, have a large range of magnification (up to 8x, or at most 10x), but due to their multi-lens system, they tend to be bigger, heavier and more expensive than Galilean telescopes.

The decision regarding a telescope depends on task demands (e.g., hands-free, duration), field of view, magnification, binocularity, and the patient's refractive error (whether this needs to be incorporated or whether the telescope can be focussed to compensate). While spotting tasks (e.g., reading signs, checking cross-walk lights) can be aided by handheld telescopes, spectacle mounted telescopes should be considered for extended tasks (e.g., watching TV, live spectator events) to prevent fatigue and improve stability. Spectacle-mounted options include those positioned in the primary position, upper bioptic or, for a telemicroscope, the lower bioptic position. Clip-on telescopes are also available. In some countries, bioptic telescopes can be used for driving. This is not generally accepted in Canada at present, but may be allowed on a case by case basis in some provinces. ${ }^{11}$

Head-mounted Video Magnifiers: Head-mounted video magnifiers are developing rapidly and becoming more widely available. These can be considered for patients who have multiple goals. These devices are typically autofocus and provide variable magnification at a range of distances plus various contrast and digital enhancement options. As a result, electronic magnifiers have been able to augment vision in more ways than a typical telescope. In one report, despite a learning curve in handling the device, visual function improvements were gained rapidly and were sustained over three months of use. Self-reported function continued to improve over that time. ${ }^{112}$ Therefore, the visual acuity obtained on the initial trial visit tends to be a good estimate of the overall improvement that the patient can expect from utilizing the device. However, it should be stated clearly to the patient that the current versions of these devices cannot be used for driving or mobility. These electronic devices tend to be of a higher cost than optical magnifiers. There is, however, a recent trend to harness the power of existing smartphones to perform similar functions as dedicated head-mounted devices but at a lower cost. ${ }^{113}$

Low vision optometrists should be aware of products which function with integrated cameras along with user input (e.g., pointing) in order to identify an object or read a passage to the patient. This information may be provided to the patient either via audio feedback or direct conduction of sound via bone. ${ }^{114,115}$ 
For any magnification device, different potential devices should be demonstrated to the patient for each task, allowing the patient to select the optimum device for their needs based on the following considerations:

- Specific task to be accomplished (e.g., requirement for hands-free)

- Duration of the task (long-term viewing versus spot-checking)

- Cosmesis (spectacle mounted versus separate device)

- Weight

- Contrast and brightness

- Cost

- Ease of use

In-office training visits followed by a take home trial are helpful, and follow-up phone calls after a month or two should be used to check for problems, difficulties with devices or further rehabilitation needs. The feasibility of telerehabilitation for low vision (training and evaluation of the patient through videoconferencing) has been considered, ${ }^{116}$ although there are no randomised controlled trials of the effectiveness of this approach ${ }^{117}$ (see Appendix B).

\section{Eccentric viewing}

Eccentric viewing is an adaptive trait that naturally develops in patients who have a dense central scotoma in the better-seeing eye. It involves the use of a preferred retinal locus (PRL) or non-foveal area which is outside the patient's scotoma area and is used for fixation. The purpose of eccentric viewing training is to aid the patient to develop a more consistent and efficient use of their natural PRL, to improve fixation stability at the PRL, to hasten the development of a PRL and/or to optimise its position. ${ }^{110,118}$ There is, of course, variability in the optimum placement of the PRL based on the size, shape and position of the scotoma. Most patients naturally place the scotoma in the superior or, unexpectedly, in the right visual field. Placement in the right visual field is not expected to be optimal for reading (when reading leftto-right). In people with normal vision, reading with a simulated scotoma is more successful using the inferior, rather than superior, visual field ${ }^{119}$, and with the scotoma moved to the left, rather than right. ${ }^{120}$ However, for people with AMD, studies have shown that reading rate is not strongly related to the position of the PRL, ${ }^{121,122}$ although Watson et al. show that reading errors were more frequent when the scotoma was positioned above or to the right. ${ }^{123}$ The clinical goal is to develop a PRL such that there is the maximum horizontal area of intact visual field extending to the right, and which is closest to the non-functioning fovea (for best VA). In the case of a symmetric, well-centred scotoma, the preference is often to move the scotoma upwards in the visual field. ${ }^{110}$

The usual components of eccentric viewing training are briefly listed in Appendix G. See Leat et al. ${ }^{110}$ for a more detailed description:

Neither the effectiveness of eccentric viewing training nor the effectiveness of one method of eccentric viewing training over another has been well-established, as there are few well controlled, high quality studies (see Appendix B). ${ }^{110,18,124}$ Many studies did not have control groups, were not masked, included other interventions concurrently with eccentric viewing training, or did not have long-term follow-up. There is some evidence that eccentric viewing training may improve near $\mathrm{VA}^{110}$ and vision for general tasks such as shopping or household chores. ${ }^{125}$ Some studies have shown slight improvements in reading speed with eccentric viewing training, ${ }^{12-128}$ while Seiple et al. demonstrated some increases in reading speed with saccade training. ${ }^{129}$ However, Hassan et al. did not find increased fixation stability, although the position of the PRL did change after traditional eccentric viewing training. ${ }^{130}$

Recently there has been increased interest in the use of biofeedback. ${ }^{131}$ Microperimetry can give a more precise measure of the central scotoma and may also incorporate biofeedback. ${ }^{126,132,133}$ Studies of these methods have been mostly longitudinal cohort studies without randomisation or masking. The results suggest some potential for these methods, but they have not been compared against traditional eccentric viewing training and can only be implemented monocularly.

The time and effort spent on eccentric viewing training may depend on the funding available. Leat et al. showed that the provision of a desk mounted video magnifier resulted in significantly faster reading than eccentric viewing 
training for patients with age-related macular degeneration. ${ }^{110}$ However, eccentric viewing training still retains a place in the range of approaches available for LVR.

A more controversial approach is yoked prism relocation to enable the patient to orientate towards, and use, their PRL. The concept behind this method is to aid steady fixation by reducing the patient's need to move his/her eyes to use their PRL. However, little consistent improvement has been demonstrated and it is not a recommended treatment at this time. ${ }^{134}$ The lack of effect may be due to refixation behind the prism or lack of accuracy in properly determining the PRL, and the purpose of this approach is unclear when a PRL already exists. In fact, one wellcontrolled randomised clinical trial of the long term effect of such prisms not only found no benefit, but reported harmful effects such as dizziness, headaches, and strain. ${ }^{135}$ Considering the increased risk of falls in low vision patients, especially older patients, yoked prism relocations strategies should be avoided.

\subsubsection{MANAGEMENT OF CONTRAST SENSITIVITY LOSS}

Reduced contrast sensitivity is the other main category of vision impairment causing disability alongside central vision impairment (VA loss) and visual field impairment. It is an additional and important measure of visual function, as poor CS may exist when VA and visual fields are fairly intact. ${ }^{136} \mathrm{CS}$ of $<1.6$ on the Pelli-Robson chart represents a visual impairment (i.e., outside the normal range). ${ }^{104,137}$ When CS is reduced to $<1.40,{ }^{14,15}$ the patient is likely to be experiencing some disabilities such as issues with mobility and resolution tasks, but when CS is $<1.00$ visual performance is severely compromised, even with appropriate magnification. For example, reading is likely to be slow even with the use of optical magnifiers. ${ }^{94-96}$

Managing contrast sensitivity loss is difficult. There are three approaches; 1 . change the task parameters so as to optimise the patient's contrast sensitivity, 2. increase the contrast of the task, 3 . use vision substitution methods.

\section{Changing the patient's contrast sensitivity}

Some patient's contrast sensitivity may be improved at lower or, more frequently, higher levels of illumination. This is one explanation for why lighting levels are critical for low vision patients. Note that increasing the illumination on print does not change the contrast of the print, but changes the contrast sensitivity of the patient. Reducing the light scatter within the eye may result in a more contrasted retinal image for some patients. This may be achieved with the use of a typoscope or electronic reverse contrast for print (white on black), which allow high illumination of the print without increasing veiling glare due to intraocular light scatter. It has been suggested that shortwave length absorbing filters also reduce light scatter within the eye, thereby enhancing the contrast of the retinal image. However, although patients do report benefit, studies show very little or no objective improvement on visual functions such as VA, contrast sensitivity, or reading with coloured filters ${ }^{108,138,139}$ (see Appendix B).

\section{Increasing the contrast of the task}

Contrast enhancement options exist in all modern video magnification devices so that poor contrast print, such as newspaper, can be electronically displayed at almost 100\% contrast. Contrast of photos and writing can be similarly increased. There are also contrast accessibility options on computers. In some head-borne electro-optical devices there are digital enhancement options such as edge enhancement, which may also help to increase the visibility of pictures, faces, TV or features in the environment.

Environment modifications, such as marking the edges of steps, stairs and doors can be considered. Techniques for increasing the contrast when eating and cooking include using plates or cups of a contrasting plain colour. For writing, use of black felt tip or marker pens, and bold-lined paper can be helpful.

\section{Vision Substitution}

When CS is very poor, sight substitution methods should be considered for speed of access to information and ease of undertaking tasks. This can be supplemental to visual access, i.e., patients do not need to commit solely to one or other strategy. Voice command and output exist on most smart technology and laptops, or specific voice output software such as Jaws, can be installed. Dedicated, stand-alone optical character recognition (OCR) scanners are available for individuals who do not use computers. Players and readers (e.g. Daisy player) may be appreciated by patients who want access to auditory books. Other options include devices such as watches, calculators and liquid level indicators with auditory output.

\subsubsection{MANAGEMENT OF PERIPHERAL FIELD LOSS}

Conditions such as retinitis pigmentosa, choroideremia, glaucoma and cerebrovascular accidents can constrict or reduce the available visual field. Patients with less than $70^{\circ}$ total solid angle of visual field are likely to experience 
mobility difficulties. ${ }^{12}$ Other difficulties that patients with peripheral field loss will encounter include more difficulty with daily living skills, dark adaptation and locating objects, resulting in an overall reduced quality of life. Patients can be helped with certain devices, techniques and training.

\section{Options for general peripheral awareness}

Prisms: For patients with homonymous hemianopia, Peli prisms or sector (spotting) prisms can be demonstrated and discussed..$^{140,141}$ There are a variety of methods for placement of prisms ${ }^{142}$ Note that sector prisms are often described as being placed on the spectacle lens on the side of the field defect, but this leads to diplopia when the patient looks through the prism. An alternative is to place a sector prism on both spectacles lenses, as shown in Appendix $\mathrm{H}^{143}$ but this still results in an apical scotoma. Peli prisms increase the visual field by creating areas of visual confusion. For a detailed discussion see Apfelbaum et al. who compared the optics of sector prisms and Peli prisms. ${ }^{144}$

Patients with overall peripheral constriction may benefit from sector prisms on both sides of the spectacles and in the lower visual field, or a channel lens.

A useful method for placing sector prisms is to slowly introduce a sticky paper, such as a Post-It Note, from the side of the visual field loss while the patient looks straight ahead. Mark the point where the patient first sees the paper, and then place the prism 1-2 mms temporally to this mark. The patient should not be aware of the edge of the prism when viewing in primary gaze. ${ }^{142,143}$ Training is a vital component for the patient's successful use of any of these prisms.

Minifiers: For patients with advanced contraction of the visual fields, minifiers, such as reverse telescopes and handheld minus lenses, can be considered. Reverse telescopes can be spectacle mounted in a bioptic position or hand held. Amorphic lenses (which have minification in the horizontal meridian only) have been available in the past.

Training: Visual search training is important in cases of significant field loss (hemianopia, constricted fields) to aid the patient to learn deliberate eye movement strategies to scan their environment. Referral for orientation and mobility training, sighted guide techniques and guide dogs are options to be considered.

\section{Options for reading for patients with field loss}

Once patients with conditions such as RP and glaucoma have significantly constricted visual fields, central vision is also often affected with both contrast sensitivity and VA being reduced. In this situation the patient may require magnification, but there is an additional limitation due to the reduced field. Too much magnification may result in poorer reading ability, if insufficient numbers of characters can be viewed at a time. In these cases, calculating magnification from the CPS may be effective. Video-magnification aids and computer software adaptations may be effective for patients with either constricted fields or hemianopia by allowing scrolling of the text through the remaining visual field, reducing the column width of the text and, for those with reduced CS, increasing contrast.

Patients with hemianopia often have difficulty tracking the line of text and tend to omit the endings or the beginnings of lines. Strategies such as marking the text margins, using line guides, and holding the print vertically or diagonally may help.

\subsubsection{MANAGEMENT OF NYSTAGMUS}

Positioning of visual material is a useful strategy for patients with nystagmus. Reading material can be positioned at the null point of nystagmus and the patient can position themselves so that the null point can be used more comfortably, without having to turn the head. For example, if the null point is to the patient's right, then visual material should be placed to their right and they would be more comfortable sitting to the left of the class or theater so their gaze is directed to the right. Yoked prisms may be used to move the null point closer to the primary position. In cases where convergence reduces the amplitude of nystagmus, base out prisms, with the incorporation of additional minus for pre-presbyopes, can be considered. Contact lenses may have benefits for patients with nystagmus, by decreasing the amplitude and possibly improving visual acuity and contrast sensitivity slightly, although not all studies have demonstrated improvements. ${ }^{145,146}$

\subsubsection{LIGHTING REQUIREMENTS}

Many patients with low vision have a limited range of light levels for optimal performance (either higher or lower light levels may be optimal) and experience more glare. 


\section{Lighting}

Lighting can be considered simultaneously with magnification, as increases in lighting may frequently change the requirement for magnification (often decreasing it). Lighting of different colour temperatures and different intensities can be demonstrated. Goose neck lamps which include LEDs of different colour temperatures are readily available and illuminance can most easily be changed by varying the distance between the page and the light source. The relationship between illumination and the distance of the light source from the page is not linear, however, but behaves according to the inverse square law. This states that the illumination is proportional to the reciprocal of the square of the light source output. In other words, bringing the light source $3 \mathrm{x}$ closer results in $9 \mathrm{x}$ more light on the page. This can be explained in simple terms and demonstrated to the patient, so that the patient is simultaneously educated about their lighting requirements. If an illuminated HM or SM is the device of choice, then the lighting is inbuilt. If this is not the case, the lighting can be specified for the patient after measuring the illuminance of the preferred lighting with a light meter (measured in Lux). This can be transposed to the lumens required for a light source at a known distance according to Appendix I. The patient can be advised about the light source that they require in terms of colour temperature and luminous output (Lumens).

The positioning of lighting is also important. Usually for close detail tasks arrange the light to be over the shoulder, so that good lighting, but not glare, is introduced. The concept of task lighting is important, i.e., that specific and adequate lighting should be positioned in the areas of the home where tasks are performed.

\section{Tints and filters}

Non-selective and selective transmission tints can be of great benefit to many patients with low vision to control light levels and glare and to optimise patient comfort. A range of filters, such as short wave-length absorbing lenses, should be available for demonstration and are available from several suppliers. Other filters, which are often selected by patients, include blue, plum, grey and polarising filters. Conventional spectacle tints in grey or grey-brown can be useful for some patients, and can be prescribed in a photochromic lens. However, these conventional spectacle tints may not be sufficient for patients who are very photophobic.

Filters are currently assessed subjectively, either indoors or outdoors or both, depending on the patient's symptoms and the situation in which they experience most glare. Generally, non-selective transmission tints should be prescribed, unless the patient specifically benefits from a selective tint, as selective tints will always distort colour perception. Although short wave-length yellow tints may be subjectively beneficial to patients with glare, currently there is no evidence that they improve contrast for reading for patients with poor contrast sensitivity or that they improve reading speed. In fact, reading speed may be decreased (see Appendix B). ${ }^{108}$ For young children, observation of the extent to which they open their eyes, relax their forehead, or lift up their head can be used to assess the optimum tint.

Filters can be prescribed in non-prescription glasses, prescription spectacles, clip-ons or fit-overs, depending on the patient's refraction and preference. For people who are very glare sensitive and photophobic, wraparound glasses or side shields should be considered. Patients with albinism or aniridia may benefit from an iris imprint contact lens with an incorporated tint, while those with achromatopsia may find a red or red-brown contact lens with a tinted pupillary zone very helpful.

\subsubsection{OTHER INTERVENTIONS AND CONSIDERATIONS Visual Training and Adaptive Strategies}

Training should take place for all devices that are prescribed or recommended. This should include how to use and clean the device and how to replace any batteries. For reading, how to scroll the print across the field of view is important for higher magnifications. Training is typically delegated to an in-house, trained optometric assistant or low vision therapist.

\section{Driving}

Patients with central vision loss or peripheral loss may fail to meet the driving standard in their province of residence. In some provinces, and most states of the US, patients can continue to drive with bioptics. In the case of visual field loss, most provinces will consider driving on a case-by-case basis. For a summary of driving requirements, and ability to use bioptics according to province, see the AAA website. ${ }^{111}$ The LV optometrist should be aware, however, that there is no clear association between moderate VA impairment, poor stereoacuity, or dependence on monocular vision and driving ability. Contrast sensitivity impairment is more consistently found to be associated 
with driving ability, while driving with visual field loss shows a large variability between individuals; some people seem able to compensate with scanning eye movements, while others are less able. ${ }^{26,147}$

\section{Non-Optical Options}

The LV optometrist should be able to recommend the following:

- Devices which give relative size magnification, i.e., increase the size of the task, such as large print books, clocks, watches

- Devices with voice or auditory output, e.g., talking clocks, blood glucose monitoring for diabetics, audio books, liquid level indicators

- Access to auditory information, e.g., talking books, auditory newscasts

- Tactile or visual markings for appliances

- Reading guides, writing guide and signing guides

- Black pens for writing

- Environmental modifications including lighting, use of contrast and de-cluttering should be discussed. Literature or websites which illustrate these modifications are helpful.

In each case, the optometrist or his/her low vision assistant should be able to supply the devices or inform the patient where they are available. The LV optometrist may develop their own printed literature or have available leaflets from various other services which illustrate these approaches.

\section{Additional Services}

The LV optometrist must be mindful of other services that may be required by the patient and refer or recommend these when indicated. For patients who require Level 3 LV (Comprehensive LVR) inter-disciplinary care is indicated. This may be provided in one location as in a multidisciplinary clinic, or by close communication between service providers. When referring, it is recommended that the optometrist include their rehabilitation plan, including what interventions that have been explored and implemented.

Additional services include:

- Orientation and mobility training

- Occupational therapy, independent living specialist assessment

- Low vision therapy

- High technology assessments

- Social and community services

- Counselling

- Genetic counseling

- Surgical consultation, e.g., for cataract, nystagmus, strabismus

- Vocational counselling 


\subsubsection{NON-VISUAL FACTORS AFFECTING THE LVR OUTCOME}

\section{Psychosocial}

The patient may be coping with the stages of grieving ${ }^{148}$ and may not have reached the stage of acceptance, when providing low vision devices is usually more successful. This may limit the success of LVR. However, the LV optometrist should still demonstrate some interventions which, if accepted, may alleviate a patient's vision specific distress $^{33,149}$ and allow for the introduction of other options in the future. The optometrist should also arrange to see the patient for follow-up appointments and suggest counselling.

The optometrist must be sensitive to the link between visual impairment and poor mental health (depression, anxiety, feelings of isolation and poor self-esteem) which can lead to increased mortality ${ }^{33,38}$ and be prepared to refer the patient for other services, such as counselling, when these are suspected. This need may be indicated by the PHQ-2 screener used at intake.

\section{Cognitive factors}

People with visual impairment are more likely to have cognitive losses. ${ }^{150}$ Specifically, better near visual acuity and having spectacles for near work seem more highly associated with higher cognitive function than the level of distance VA. ${ }^{15-153}$ Significantly, there is evidence that visual impairment precedes cognitive loss or dementia (i.e., is a likely causative factor) and this remains true when adjusting for other factors, such as educational level, income or hearing loss. ${ }^{151,154-158}$ Also, in several studies, vision loss was more predictive of cognitive decline than hearing loss. ${ }^{153,157,159}$

Therefore, treatment for vision loss, including refractive correction or visual rehabilitation, may help to prevent cognitive loss or improve cognition. There is evidence that treatment of cataract ${ }^{160-162}$ or other eye disease $\mathrm{e}^{154}$ helps to improve cognitive function or prevent cognitive decline. There are fewer studies regarding LVR. Meyniel et al. documented that patients with cognitive impairment who underwent four months of LVR improved in their average cognitive function. ${ }^{163}$ Zheng et al. concluded that maintaining good vision, in particular near vision, may help protect against cognitive decline in older years. ${ }^{158}$ One proposed mechanism for the prevention of cognitive decline is the ability to continue cognitively stimulating activities, such as reading, and maintain social networking. ${ }^{154,158}$ If this mechanism proves correct, then visual rehabilitation should not only enable patients to perform desired tasks and improve quality of life, but also enable them to maintain cognitive function.

Lastly, a different issue relating to cognitive impairment and LVR is the extent to which patients with cognitive impairment may benefit from LVR. There are some cohort studies which address this question. Hagerman et al. reported that patients with cognitive impairment attained improvements in VA with devices. ${ }^{164}$ Whitson et al. trialed an enhanced low vision rehabilitation programme in a small cohort of people with cognitive deficits and demonstrated improvements in vision and cognitive function. Patients were able to benefit from training with a CCTV. ${ }^{165}$ Gervais et al. in Quebec described a case series of patients and concluded that cognitive deficits do not preclude successful LVR. ${ }^{166}$

\section{Co-morbidities}

Other co-morbidities will impact the effectiveness of the LVR plan. For example, patients with diabetes may have more difficulty adapting to vision loss, while those with paresis due to stroke or arthritis will have physical difficulty managing hand-held low vision devices. Post-stroke patients experience a wide range of both visual and systemic difficulties in addition to hemianopia. These include paresis, perceptual changes (such as neglect and midline shift), incommitancies with variable diplopia, loss of visual acuity and aphasia. These need to be addressed and taken into consideration in the rehabilitation plan and may require referral for optometric neurorehabilitation, which is outside the scope of this Guideline.

Patients with developmental delays represent a population with unique needs. In this population, the emphasis is to first undertake a good visual function assessment (description of visual abilities). From this evaluation, recommendations regarding optimum lighting, size, contrast, crowding (or lack of) and positioning of visual information, use of good colour contrast, vision stimulation, vision therapy, and refractive correction can be made. ${ }^{167}$

\section{Age}

LVR should be considered from the moment that a child is diagnosed with a condition which results in a visual impairment. Such a diagnosis in a child has been described as a rehabilitation emergency and there are specific approaches for young infants, which are beyond the scope of this document. In fact, this is described as habilitation (rather than 
rehabilitation) as the child has not lost skills, but rather needs help to develop skills in the first place. ${ }^{168,169}$ For an approach to Pediatric Low Vision Rehabilitation see Leat (2015). ${ }^{168}$

LVR should not preclude older adults either. Jackson et al. found that female patients aged 85 years and older gained as much benefit from LVR in overall ability and reading ability as younger patients (though not in mobility). ${ }^{170}$

\section{CONCLUSION}

LVR is an on-going process for most patients and follow-up is important. Vision may alter and new devices become available. Patients' acceptance level, activities and goals may change over time. Patients describe it as a journey. Most patients, especially those with poorer vision, will require multiple devices and strategies for different tasks, and these may be added over time.

To conclude, optometrists are uniquely qualified to provide LVR as they can undertake refraction, optimise visual function with spectacles and contact lenses, accurately assess visual function and understand the impact of ocular conditions, develop a vision rehabilitation plan, prescribe optical and non-optical, hand held and spectacle mounted devices, provide vision training, advise about visual strategies and environmental modifications, and co-ordinate with other services. LVR requires a holistic approach to the patient, and the LV optometrist must be mindful of the emotional and psychological state of the patient. Lastly, interventions that are recommended should not only be task(s) specific, but also patient specific, i.e., tailored for each particular patient's goals, requirements and limitations.

\section{Acknowledgements}

We would like to thank Roanne Flom and Nicole Ross for reviewing this document and providing detailed feedback. We also thank Douglas Brunton and Kristin Snell for proof reading the document. 


\section{Provincial Health funding for Low Vision Assessments and Devices}

\section{Courtesy of, and adapted from: Shamrozé Khan and Susan Leat}

Note that lack of funding does not preclude optometrists from providing LV assessment and devices privately. Funding is listed when known. BCVA = Best Corrected Visual Acuity

\begin{tabular}{|c|c|c|}
\hline $\begin{array}{l}\text { Province/ } \\
\text { Territory }\end{array}$ & LV Assessment by Optometrist & Low Vision Devices \\
\hline Canada-wide & $\begin{array}{l}\text { Funding up to a maximum exists for some } \\
\text { veterans. }\end{array}$ & $\begin{array}{l}\text { Funding up to a maximum exists for some } \\
\text { veterans. They may be required to access } \\
\text { provincial funding first. }\end{array}$ \\
\hline Canada-wide & $\begin{array}{l}\text { There may be coverage for seniors, those on } \\
\text { income support programmes, employees through } \\
\text { the employer, children, and through 3rd party } \\
\text { insurance. }\end{array}$ & $\begin{array}{l}\text { There may be coverage for seniors, those on } \\
\text { income support programmes, employees through } \\
\text { the employer, children, and through } 3^{\text {rd }} \text { party } \\
\text { insurance. Devices that are medically necessary } \\
\text { may be covered through special requests. }{ }^{171}\end{array}$ \\
\hline PEI & None & None \\
\hline Nova Scotia & $\begin{array}{l}\text { Yes, low vision assessment once every } 2 \text { years can } \\
\text { be billed at } 30 \text { Medical Service Units (MSU) with } \\
\text { one mandatory follow up ( } 15 \text { MSU). Acuity must } \\
\text { be at least } 20 / 50 \text { or worse in the better eye. }\end{array}$ & None \\
\hline $\begin{array}{l}\text { Newfoundland and } \\
\text { Labrador }\end{array}$ & None & None \\
\hline New Brunswick & None & None \\
\hline Quebec & $\begin{array}{l}\text { Restricted. There is a fee for an optometrist ( } \$ 70) \\
\text { doing a LV assessment in their office for people } \\
\text { who meet the QC definition of visual impairment } \\
\text { (as below) and }<19 \text { or }>65 \text { years old. } \\
\text { Covered for all ages if seen in Government funded } \\
\text { Multi-disciplinary Rehabilitation Centers. There } \\
\text { are } 18 \text { of these centers across the province. }{ }^{172} \text { The } \\
\text { eligibility criteria and the list of visual aids can be } \\
\text { found on the RAMQ website. }{ }^{173} \text { Patients who meet } \\
\text { the visual criteria can be seen by the optometrist } \\
\text { and all the other professionals (OT, psychologist, } \\
\text { mobility instructor, etc...) for free in these centers } \\
\text { if they have a valid RAMQ card. } \\
\text { Eligibility criteria are a BCVA of less than } 6 / 21 \text { in } \\
\text { each eye or a visual field of less than } 60 \text { in the } \\
\text { horizontal and vertical meridians or complete } \\
\text { hemianopia or a VA of } 6 / 18 \text { or less "for persons } \\
\text { who suffer from a degenerative visual problem, } \\
\text { visual impairment, physical deficiency (motor, } \\
\text { hearing or speech), or an intellectual disability". }\end{array}$ & $\begin{array}{l}\text { LV devices (long cane, magnifier, CCTV, etc...) } \\
\text { are covered and provided on on-going loan only } \\
\text { when the patient is evaluated through one of the } \\
\text { government-sponsored rehabilitation centres and } \\
\text { when they meet specific criteria which depend } \\
\text { on the device (e.g., CCTV are covered for patients } \\
\text { whose VA is } 6 / 60 \text { or less) and based upon the } \\
\text { patient's need (e.g., require it for study or work or } \\
\text { who live alone). }\end{array}$ \\
\hline Ontario & None & $\begin{array}{l}\text { Assistive Devices Program (ADP) provides partial } \\
\text { coverage (up to } 75 \%, 100 \% \text { for those on income } \\
\text { supports) for both low and high tech devices. } \\
\text { Available for a person who "is unable to perform } \\
\text { common everyday, age-related visual tasks due to } \\
\text { reduced visual functioning level" Devices must be } \\
\text { prescribed by Optometrists registered with ADP. } \\
\text { There is a lease programme for CCTVs. }{ }^{174}\end{array}$ \\
\hline
\end{tabular}




\begin{tabular}{|c|c|c|}
\hline $\begin{array}{l}\text { Province/ } \\
\text { Territory }\end{array}$ & LV Assessment by Optometrist & Low Vision Devices \\
\hline Manitoba & $\begin{array}{l}\text { Partial. Per diem available for services provided } \\
\text { through VLRC, but not when provided without } \\
\text { VLRC. }\end{array}$ & \\
\hline Alberta & $\begin{array}{l}\text { Partial. For ages }<19 \text { and }>64, \text { B } 660 \text { "Examination } \\
\text { for low vision aid" can be billed if the optometrist } \\
\text { has specific equipment and a certain number of } \\
\mathrm{LV} \text { devices available, and can demonstrate or refer } \\
\text { for non-optical aids, electronic aids and O and M } \\
\text { assessment. }\end{array}$ & $\begin{array}{l}\text { The CNIB Specialized Technical Equipment } \\
\text { Program (STEP) }{ }^{175} \text { is a government-funded } \\
\text { subsidy program administered through VLRC } \\
\text { service centres. }{ }^{176} \text { Coverage for up to } 75 \% \text { of } \\
\text { device cost if patient qualifies (VA is } 20 / 200 \text { or } \\
\text { poorer or the visual field is severely restricted and } \\
\text { based on financial need) and up to } 100 \% \text { if low } \\
\text { income. But only } 40 \% \text { of those that apply receive } \\
\text { the funding. This includes high-tech aids such as } \\
\text { CCTVs, Zoomtext, computer software, OCR. } \\
\text { Those with a BCVA of less than } 20 / 70 \text { or with } \\
\text { severely restricted visual fields, can qualify for } \\
\text { assistance for low-tech aids. }\end{array}$ \\
\hline Saskatchewan & $\begin{array}{l}\text { Restricted. Only covered if provided at the Low } \\
\text { Vision Clinic at the Pasqua Hospital upon referral } \\
\text { by an optometrist or ophthalmologist. }\end{array}$ & $\begin{array}{l}\text { Coverage and subsidies for some devices } \\
\text { through the Saskatchewan Aids to } \\
\text { Independent Living (SAIL) programme, } \\
\text { which is operated though CNIB/Vision Loss } \\
\text { Rehabilitation Saskatchewan. }{ }^{69,177} \text { Eligibility } \\
\text { depends on the device and the level of VA. For } \\
\text { example, conventional hand-held and stand } \\
\text { illuminated magnifiers are funded at VA of } 20 / 70 \\
\text { and poorer; various high technology devices } \\
\text { at VA of } 20 / 150 \text { or worse or fields of less than } \\
20 \text { degrees; digital portable video magnifiers } \\
\text { and iPad at } 20 / 200 \text { and poorer. Telescopes/ } \\
\text { spectacle mounted telescopes are only covered } \\
\text { though Labour Market Services. Low vision } \\
\text { clinic services are available for children with } \\
\text { any level of reduced acuity. Tints are covered for } \\
\text { children through SAID but require an OD report } \\
\text { requesting this because of medical necessity. }=\end{array}$ \\
\hline British Columbia & $\begin{array}{l}\text { Partial. The MSP code } 2892 \text { is billable every } 6 \\
\text { months if the optometrist has the appropriate } \\
\text { equipment. There are other MSP fees that may } \\
\text { be billed in conjunction with the } 2892 \text { code. The } \\
\text { optometrists must obtain prior approval to bill } \\
\text { these codes. Balance billing is allowed. }\end{array}$ & None \\
\hline \multicolumn{3}{|l|}{ Nunavut } \\
\hline $\begin{array}{l}\text { Northwest } \\
\text { Territories }\end{array}$ & $\begin{array}{l}\text { Partial. On application, Government funds eye } \\
\text { clinic and travel to communities. }\end{array}$ & \\
\hline Yukon & None & \\
\hline
\end{tabular}




\section{Summary of Systematic Reviews of Low Vision Interventions}

RCT = Randomised Controlled Trial; QoL = Quality of Life; LVS = Low Vision Services; AMD = Age-related Macular Degeneration; PRL= Preferred Retinal Locus; O\&M = Orientation and Mobility; ADL = Activities of Daily Living; IADL = Instrumental Activities of Daily Living

\begin{tabular}{|c|c|c|c|c|c|}
\hline $\begin{array}{l}\text { Authors, } \\
\text { Year, title }\end{array}$ & Main question & Inclusion criteria & Search results & Main conclusions & Comments \\
\hline $\begin{array}{l}\text { Barker et } \\
\text { al., } 2015^{178}\end{array}$ & $\begin{array}{l}\text { The effectiveness of } \\
\text { optical aids compared } \\
\text { to standard optical } \\
\text { refractive correction } \\
\text { in children and young } \\
\text { people with low vision }\end{array}$ & $\begin{array}{l}\text { RCTs or quasi } \\
\text { RCTs, including } \\
\text { within person } \\
\text { designs, children } \\
\text { and young people } \\
\text { aged 5-16 years }\end{array}$ & $\begin{array}{l}\text { No studies met } \\
\text { the inclusion } \\
\text { criteria }\end{array}$ & $\begin{array}{l}\text { There is a lack of high } \\
\text { quality evidence of } \\
\text { the effectiveness of } \\
\text { optical aids for this } \\
\text { age group. }\end{array}$ & $\begin{array}{l}\text { Very strict } \\
\text { inclusion criteria, } \\
\text { so lower levels } \\
\text { of evidence not } \\
\text { assessed }\end{array}$ \\
\hline $\begin{array}{l}\text { Binns et al., } \\
2012^{46}\end{array}$ & $\begin{array}{l}\text { The effectiveness of } \\
\text { different models of } \\
\text { LVS provision }\end{array}$ & Not clearly stated & $\begin{array}{l}58 \text { studies met } \\
\text { the liberal } \\
\text { inclusion } \\
\text { criteria of } \\
\text { which } 7 \text { were } \\
\text { RCTs }\end{array}$ & $\begin{array}{l}\text { There is sufficient } \\
\text { evidence to confirm } \\
\text { that low vision } \\
\text { rehabilitation } \\
\text { improves clinical and } \\
\text { functional outcomes. } \\
\text { Despite different } \\
\text { models of LV care, } \\
\text { most studies showed } \\
\text { improvement in } \\
\text { functional ability. Less } \\
\text { clear evidence on QoL } \\
\text { outcomes. }\end{array}$ & $\begin{array}{l}\text { The authors were } \\
\text { unable to conclude } \\
\text { whether one model } \\
\text { of LV service is } \\
\text { better than another. }\end{array}$ \\
\hline $\begin{array}{l}\text { Bittner et } \\
\text { al., } 2015^{117}\end{array}$ & $\begin{array}{l}\text { To compare the effects } \\
\text { of telerehabilitation } \\
\text { with face-to-face (e.g., } \\
\text { in-office or inpatient) } \\
\text { vision rehabilitation } \\
\text { services for improving } \\
\text { vision-related QoL } \\
\text { and reading speed in } \\
\text { people with visual } \\
\text { function loss }\end{array}$ & $\begin{array}{l}\text { RCTs, } \\
\text { Patients with any } \\
\text { cause of vision } \\
\text { loss }\end{array}$ & $\begin{array}{l}\text { No studies met } \\
\text { the inclusion } \\
\text { criteria }\end{array}$ & $\begin{array}{l}\text { There is a need for } \\
\text { clinical trials to } \\
\text { explore this mode of } \\
\text { delivery }\end{array}$ & \\
\hline $\begin{array}{l}\text { Gaffney et } \\
\text { al., } 2014^{118}\end{array}$ & $\begin{array}{l}\text { The effectiveness of } \\
\text { eccentric viewing and } \\
\text { steady eye strategy } \\
\text { training in people with } \\
\text { central vision loss }\end{array}$ & $\begin{array}{l}\text { Participants with } \\
\text { central vision loss } \\
\text { (simulated central } \\
\text { scotoma studies } \\
\text { were excluded). } \\
\text { Studies with } \\
\text { a comparison } \\
\text { (before or after } \\
\text { studies or a } \\
\text { control group) }\end{array}$ & $\begin{array}{l}36 \text { studies of } \\
\text { which } 3 \text { were } \\
\text { RCTs }\end{array}$ & $\begin{array}{l}\text { Eccentric viewing } \\
\text { and steady eye } \\
\text { strategy training can } \\
\text { improve near visual } \\
\text { acuity, reading speed, } \\
\text { and performance } \\
\text { of activities of daily } \\
\text { living. Insufficient } \\
\text { literature to establish } \\
\text { a relationship between } \\
\text { training and distance } \\
\text { visual acuity or quality } \\
\text { of life. No conclusive } \\
\text { evidence to show that } \\
\text { a particular model } \\
\text { of eccentric viewing } \\
\text { training is superior } \\
\text { to another and little } \\
\text { evidence regarding the } \\
\text { outcome and duration } \\
\text { of training. }\end{array}$ & $\begin{array}{l}\text { Most studies were } \\
\text { judged to be of very } \\
\text { low quality and } \\
\text { open to risk of bias. } \\
\text { The } 3 \text { RCTs were } \\
\text { not well-designed } \\
\text { studies and one } \\
\text { confounded the } \\
\text { effects of EV } \\
\text { training and } \\
\text { devices. }\end{array}$ \\
\hline
\end{tabular}




\begin{tabular}{|c|c|c|c|c|c|}
\hline $\begin{array}{l}\text { Authors, } \\
\text { Year, title }\end{array}$ & Main question & Inclusion criteria & Search results & Main conclusions & Comments \\
\hline $\begin{array}{l}\text { Hamade et } \\
\text { al., } 2016^{179}\end{array}$ & $\begin{array}{l}\text { The effect of } \\
\text { various low-vision } \\
\text { rehabilitation } \\
\text { strategies on reading } \\
\text { speed and depression } \\
\text { in patients } 55 \text { and older } \\
\text { with AMD }\end{array}$ & $\begin{array}{l}\text { Sample size of } \\
\geq 20 \text { eyes. RCT } \\
\text { or observational } \\
\text { studies from } \\
\text { the year } 2000 \\
\text { onwards, studies } \\
\text { including an } \\
\text { outcome of } \\
\text { reading speed or } \\
\text { depression scores }\end{array}$ & $\begin{array}{l}9 \text { studies, } 6 \\
\text { studies on } \\
\text { reading speed } \\
\text { ( } 2 \text { RCTs) and } 3 \\
\text { on depression } \\
\text { ( } 2 \text { RCTs) }\end{array}$ & $\begin{array}{l}\text { Overall, a significant } \\
\text { improvement in } \\
\text { reading speed was } \\
\text { found. There was } \\
\text { a non-significant } \\
\text { improvement in } \\
\text { depression scores. }\end{array}$ & $\begin{array}{l}\text { The number of } \\
\text { included studies } \\
\text { was small because } \\
\text { reading speed was } \\
\text { defined as the only } \\
\text { outcome measure. } \\
\text { The meta-analysis } \\
\text { combined difference } \\
\text { interventions for } \\
\text { reading (relocation } \\
\text { prisms, eccentric } \\
\text { viewing training, } \\
\text { training with } \\
\text { devices). The risk } \\
\text { of bias was judged } \\
\text { as moderate to very } \\
\text { high for all reading } \\
\text { studies except for } \\
\text { one, and as high for } \\
2 \text { of the } 3 \text { studies on } \\
\text { depression. }\end{array}$ \\
\hline $\begin{array}{l}\text { Howe, } \\
2012^{124}\end{array}$ & $\begin{array}{l}\text { To compare protocols } \\
\text { for eccentric viewing } \\
\text { training and study } \\
\text { factors which might } \\
\text { predict outcomes }\end{array}$ & $\begin{array}{l}\text { Broad inclusion } \\
\text { criteria for } \\
\text { type of study. } \\
\text { Should include } \\
\text { a treatment } \\
\text { description, } \\
\text { participants } \\
\text { with low vision } \\
\text { (not simulated } \\
\text { central scotoma), } \\
\text { outcome of } \\
\text { reading rate. }\end{array}$ & $\begin{array}{l}16 \text { studies (1 } \\
\text { RCT). Most } \\
\text { were before } \\
\text { and after } \\
\text { studies with } \\
\text { one group. }\end{array}$ & $\begin{array}{l}\text { No significant } \\
\text { difference in reading } \\
\text { speed based on } \\
\text { different methods } \\
\text { of eccentric viewing } \\
\text { training. Eccentric } \\
\text { viewing training is } \\
\text { effective to improve } \\
\text { vision. There was a } \\
\text { negative correlation } \\
\text { between final reading } \\
\text { speed and age. }\end{array}$ & $\begin{array}{l}\text { Some studies } \\
\text { included other } \\
\text { methods in addition } \\
\text { to eccentric viewing } \\
\text { training such } \\
\text { as training with } \\
\text { devices, refractive } \\
\text { correction, and } \\
\text { optimal lighting. } \\
\text { This systematic } \\
\text { review did not have } \\
\text { a second reviewer } \\
\text { to select the } \\
\text { included studies. }\end{array}$ \\
\hline $\begin{array}{l}\text { Jutai et al., } \\
2009^{180}\end{array}$ & $\begin{array}{l}\text { For adults with low } \\
\text { vision, what is the } \\
\text { effectiveness of } \\
\text { commonly prescribed } \\
\text { assistive technology } \\
\text { interventions for } \\
\text { rehabilitation? }\end{array}$ & $\begin{array}{l}\text { Assistive } \\
\text { technology } \\
\text { included optical } \\
\text { magnification, } \\
\text { prisms, training, } \\
\text { telescopes, video } \\
\text { magnifiers, } \\
\text { illumination, } \\
\text { computer } \\
\text { adaptations, } \\
\text { filters }\end{array}$ & $\begin{array}{l}108 \text { studies (24 } \\
\text { RCTs) }\end{array}$ & $\begin{array}{l}\text { There were too few } \\
\text { studies to recommend } \\
\text { video-magnification } \\
\text { over optical } \\
\text { magnification. There } \\
\text { is limited evidence } \\
\text { comparing different } \\
\text { prism systems for } \\
\text { field enhancement in } \\
\text { hemianopia. One high } \\
\text { quality study showed } \\
\text { that yoked prisms } \\
\text { for relocation of the } \\
\text { PRL in AMD are not } \\
\text { effective. Lighting is } \\
\text { likely to increase the } \\
\text { benefit of optical aids } \\
\text { for reading, but there is } \\
\text { less evidence regarding } \\
\text { the specific level of } \\
\text { illumination. There is } \\
\text { only weak evidence } \\
\text { concerning the benefits } \\
\text { of filters for reading. } \\
\text { There is moderately } \\
\text { strong evidence that } \\
\text { people with AMD } \\
\text { benefit from computer } \\
\text { adaptations, specifically, } \\
\text { size of icons. }\end{array}$ & $\begin{array}{l}\text { Only } 10 \text { studies } \\
\text { were included } \\
\text { for detailed } \\
\text { description. }\end{array}$ \\
\hline
\end{tabular}




\begin{tabular}{|c|c|c|c|c|c|}
\hline $\begin{array}{l}\text { Authors, } \\
\text { Year, title }\end{array}$ & Main question & Inclusion criteria & Search results & Main conclusions & Comments \\
\hline $\begin{array}{l}\text { Liu et al., } \\
2013^{181}\end{array}$ & $\begin{array}{l}\text { The effectiveness } \\
\text { of interventions } \\
\text { within the scope of } \\
\text { occupational therapy } \\
\text { to maintain, restore } \\
\text { and improve ADLs } \\
\text { and IADLs at home for } \\
\text { older adults with low } \\
\text { vision }\end{array}$ & Not clearly stated & 17 studies & $\begin{array}{l}\text { Multicomponent } \\
\text { approaches were } \\
\text { effective. These } \\
\text { included group } \\
\text { sessions compared } \\
\text { to usual care or } \\
\text { recorded information. } \\
\text { Single intervention } \\
\text { was effective. } \\
\text { Multidisciplinary low } \\
\text { vision intervention is } \\
\text { effective. }\end{array}$ & $\begin{array}{l}\text { The single } \\
\text { intervention } \\
\text { studies included } \\
\text { disparate } \\
\text { interventions } \\
\text { (training with } \\
\text { devices, eccentric } \\
\text { viewing training, } \\
\text { prisms or full LVR). } \\
\text { Multidisciplinary } \\
\text { intervention } \\
\text { studies, which } \\
\text { compared } \\
\text { LVR with and } \\
\text { without an extra } \\
\text { intervention, } \\
\text { such as home } \\
\text { visits, found no } \\
\text { difference. }\end{array}$ \\
\hline $\begin{array}{l}\text { Rees et al., } \\
2010^{182}\end{array}$ & $\begin{array}{l}\text { Outline the current } \\
\text { evidence for the } \\
\text { impact of low- } \\
\text { vision rehabilitation } \\
\text { programs on } \\
\text { psychological well- } \\
\text { being. Describe and } \\
\text { summarize the effects } \\
\text { of novel interventions } \\
\text { designed specifically to } \\
\text { address psychological } \\
\text { needs in people with } \\
\text { vision impairment. }\end{array}$ & $\begin{array}{l}\text { Randomised, non- } \\
\text { randomised and } \\
\text { pre-post studies, } \\
\text { participants } \\
\text { 18+ years, with } \\
\text { outcomes } \\
\text { of mental } \\
\text { health, anxiety, } \\
\text { depression, self- } \\
\text { efficacy or coping } \\
\text { scales }\end{array}$ & $\begin{array}{l}30 \text { studies (10 } \\
\text { RCTs) }\end{array}$ & $\begin{array}{l}\text { Multidisciplinary low } \\
\text { vision rehabilitation } \\
\text { services may } \\
\text { improve aspects of } \\
\text { psychological well- } \\
\text { being such as vision } \\
\text { specific quality of } \\
\text { life, but has little } \\
\text { impact on depression. } \\
\text { Specifically designed } \\
\text { psychological group } \\
\text { and individual } \\
\text { programs added } \\
\text { to other low vision } \\
\text { rehabilitation } \\
\text { improved a range } \\
\text { of psychological } \\
\text { outcomes. }\end{array}$ & $\begin{array}{l}\text { It is not clear } \\
\text { which aspects of } \\
\text { multidisciplinary } \\
\text { services may } \\
\text { improve } \\
\text { psychological } \\
\text { function. There } \\
\text { are few studies } \\
\text { which compare } \\
\text { multidisciplinary } \\
\text { service with } \\
\text { optometric low } \\
\text { vision provision. }\end{array}$ \\
\hline $\begin{array}{l}\text { Skelton et } \\
\text { al., } 2013^{183}\end{array}$ & $\begin{array}{l}\text { The effectiveness of } \\
\text { environmental } \\
\text { and behavioural } \\
\text { interventions in } \\
\text { reducing activity } \\
\text { limitation and } \\
\text { improving QoL among } \\
\text { visually impaired older } \\
\text { people }\end{array}$ & $\begin{array}{l}\text { RCTs or quasi } \\
\text { RCTs, people } \\
60+\text { years, living } \\
\text { independently } \\
\text { or in residential } \\
\text { settings, studies } \\
\text { with compared } \\
\text { environmental } \\
\text { interventions, } \\
\text { behavioural } \\
\text { interventions } \\
\text { or both, versus } \\
\text { control (placebo } \\
\text { control or no } \\
\text { intervention } \\
\text { or usual care), } \\
\text { or comparing } \\
\text { different types of } \\
\text { environmental } \\
\text { or behavioural } \\
\text { intervention, must } \\
\text { have a physical } \\
\text { activity as an } \\
\text { outcome }\end{array}$ & $\begin{array}{l}\text { No studies } \\
\text { which met } \\
\text { criteria }\end{array}$ & $\begin{array}{l}\text { Further research is } \\
\text { necessary to consider } \\
\text { the effectiveness of } \\
\text { environmental } \\
\text { and behavioural } \\
\text { interventions such } \\
\text { as orientation and } \\
\text { mobility training on } \\
\text { physical activity, falls } \\
\text { and quality of life in } \\
\text { older adults with low } \\
\text { vision, and the effect } \\
\text { of an occupational } \\
\text { therapist delivering } \\
\text { home safety } \\
\text { modification, coping } \\
\text { strategies and exercise } \\
\text { with older people } \\
\text { with low vision. }\end{array}$ & \\
\hline
\end{tabular}




\begin{tabular}{|c|c|c|c|c|c|}
\hline $\begin{array}{l}\text { Authors, } \\
\text { Year, title }\end{array}$ & Main question & Inclusion criteria & Search results & Main conclusions & Comments \\
\hline $\begin{array}{l}\text { Thomas et } \\
\text { al., } 2-15^{184}\end{array}$ & $\begin{array}{l}\text { The effect of electronic } \\
\text { assistive technologies } \\
\text { on reading, educational } \\
\text { outcomes and quality } \\
\text { of life in children and } \\
\text { young people with low } \\
\text { vision }\end{array}$ & $\begin{array}{l}\text { RCT or quasi } \\
\text { RCTs, children } \\
\text { and young } \\
\text { people aged 5-16 } \\
\text { years, studies } \\
\text { which compare } \\
\text { electronic devices } \\
\text { with optical } \\
\text { aids, studies } \\
\text { which compared } \\
\text { different } \\
\text { electronic devices } \\
\text { with each other }\end{array}$ & $\begin{array}{l}\text { No studies } \\
\text { which met } \\
\text { criteria }\end{array}$ & $\begin{array}{l}\text { High quality } \\
\text { studies are needed } \\
\text { to compare the } \\
\text { usefulness of assistive } \\
\text { technology for } \\
\text { children and young } \\
\text { people. }\end{array}$ & \\
\hline $\begin{array}{l}\text { Virgili and } \\
\text { Rubin, } \\
2010^{185}\end{array}$ & $\begin{array}{l}\text { To assess the effects } \\
\text { of O\&M training, with } \\
\text { or without associated } \\
\text { devices, for adults with } \\
\text { low vision }\end{array}$ & $\begin{array}{l}\text { RCTs or quasi } \\
\text { RCTs which } \\
\text { compared O\&M } \\
\text { training with no } \\
\text { training }\end{array}$ & $\begin{array}{l}2 \text { small related } \\
\text { quasi-RTCs }\end{array}$ & $\begin{array}{l}\text { Low quality studies } \\
\text { which compared } \\
\text { training to physical } \\
\text { exercise. Training had } \\
\text { no significant effect. }\end{array}$ & $\begin{array}{l}\text { Very strict } \\
\text { inclusion criteria, } \\
\text { so lower levels } \\
\text { of evidence not } \\
\text { assessed. }\end{array}$ \\
\hline $\begin{array}{l}\text { Virgili et al., } \\
2018^{108}\end{array}$ & $\begin{array}{l}\text { To assess the effects of } \\
\text { different visual reading } \\
\text { aids for adults with low } \\
\text { vision }\end{array}$ & $\begin{array}{l}\text { RCTs or quasi- } \\
\text { RCTs which } \\
\text { compared } \\
\text { different devices } \\
\text { for reading. } \\
\text { Studies that } \\
\text { compared a } \\
\text { device with no } \\
\text { device were } \\
\text { excluded. } \\
\text { Magnifying } \\
\text { devices, filters } \\
\text { and prisms were } \\
\text { included. }\end{array}$ & 13 studies & $\begin{array}{l}\text { Reading speed may } \\
\text { be higher with } \\
\text { stand-mounted } \\
\text { video magnifiers } \\
\text { than optical devices } \\
\text { (low certainty) and } \\
\text { reading duration was } \\
\text { longer with electronic } \\
\text { devices (moderate } \\
\text { certainty). There } \\
\text { was less evidence } \\
\text { for head-mounted or } \\
\text { portable devices. No } \\
\text { important difference } \\
\text { between head- } \\
\text { mounted and stand } \\
\text { video magnifiers (low } \\
\text { certainty) or between } \\
\text { tablet computer and } \\
\text { desk video magnifiers. } \\
\text { There is no good } \\
\text { evidence to support } \\
\text { the use of prism } \\
\text { relocation spectacles } \\
\text { or coloured filters } \\
\text { for reading. Reading } \\
\text { speed may be } \\
\text { decreased with } \\
\text { coloured filters. }\end{array}$ & $\begin{array}{l}\text { The authors } \\
\text { concluded that } \\
\text { there is insufficient } \\
\text { evidence to support } \\
\text { the specific type } \\
\text { of electronic or } \\
\text { optical device } \\
\text { for most low } \\
\text { vision aid users, } \\
\text { although stand- } \\
\text { mounted video } \\
\text { magnifiers may } \\
\text { improve reading } \\
\text { speed compared to } \\
\text { optical devices. }\end{array}$ \\
\hline
\end{tabular}


Appendix C

\section{Levels of Low Vision Service}

Authors: Drs Susan J. Leat, Tammy Labreche and Shamrozé Khan

School of Optometry and Vision Science, University of Waterloo

Revised April 2019

LEVEL 1 SCREENING AND RECOGNITION OF A LV PATIENT

It is the responsibility and minimum standard of care expected of all optometrists to either directly provide Low Vision Rehabilitation (LVR), or recommend or refer for a LVR by a low vision optometrist prior to referral to other agencies. Referral should be as soon as the patient is experiencing permanent low vision, despite referrals for other treatment or on-going treatment.

Low vision assessment and rehabilitation should always be recommended for the following:

- A patient who has low vision which is defined as a visual impairment (measurable loss of vision) resulting in a visual disability (difficulty undertaking a task because of poor vision).

- To clarify, this includes all patients who have

- An incurable disease or injury (ocular or systemic) for which available surgical or medical treatment has been undertaken, considered or is on-going

AND

- Reduced corrected vision (most commonly impairment of VA, CS or visual fields) compared to age norms

AND

- Difficulty with desired visual tasks despite optimum optical correction

- In terms of visual impairment, the levels at which vision loss is likely to cause a visual disability are (but not limited to) the following

- VA 6/12 (20/40) or poorer

OR

- Central or paracentral scotoma or metamorphopsia

OR

- Peripheral field loss (hemianopia or quadrantanopia; less than 70 degrees $^{1}$ circular diameter total field) OR

- $\log \mathrm{CS}<1.4$

OR

- A combination of these measures

Minimum additional assessment: It is important to ascertain a patient's self-reported disabilities, functional vision and goals. An accurate refraction (ideally with a trial frame) and measurement of best corrected VA are important. All optometrists should be willing and able to trial a higher reading addition (up to 4D). An assessment of contrast sensitivity and visual fields is highly recommended to complete the information required to make an accurate referral.

Minimum additional equipment: A contrast sensitivity chart such as Pelli-Robson chart, Mars Perceptrix Contrast Sensitivity Chart, Sloan Letter Low Contrast Flip Chart or the Rabin Contrast Sensitivity Test.

LEVEL 2 BASIC LV SERVICE

This level of LVR can be provided in an optometrist's office with a modest amount of equipment and optical devices, and ideally with the in-office support of a trained optometric technician/assistant or low vision therapist.

1 This includes 60 degrees which is the level for funding in Quebec 
Patients who are likely to benefit are those with:

- VA from 6/12 to 6/21 inclusive and/or Log CS between 1.40 and 1.00

- No hemianopia or quadrantanopia, and circular visual field larger than 70 degrees ${ }^{1}$

- No significant paracentral field loss which limits reading speed or visual function

\section{Minimum additional equipment and devices should include:}

- Suitable distance acuity charts to quantify any visual acuity impairment better than HM (Bailey-Lovie chart, ETDRS chart, Feinbloom Low Vision Visual Acuity Book, Feinbloom PV numbers, Lea Numbers Low Vision Book).

- A logMAR continuous text reading acuity chart such as MNRead Chart, Colenbrander Continuous Text Near Vision Card, or Lighthouse Continuous Text

- Trial lens set for demonstration of high adds/microscopes and possibly a separate set of prism half-eyes/ readers and microscopes

- Hand magnifiers (e.g., 8D, 10D, 12D, 16D) (a range of illuminated and non-illuminated, pocket-sized and larger)

- Stand magnifiers up to $4 \mathrm{x}$

- Tint samples (e.g., grey, brown, yellow, orange, plum);

- Low powered monocular and binocular telescopes (e.g., up to 2-4x handheld and spectacle-mounted)

- Ideally, a good gooseneck lamp for demonstration of lighting

- Possibly a pocket video magnifier (note that patients who benefit significantly from this should be assessed for a desktop CCTV if possible, as well as other tertiary LVR)

A minimum database of necessary testing would be, but is not limited to:

a. Comprehensive history including identification of patient goals

b. Distance and near acuity testing with appropriate charts

c. Objective refraction and subjective trial frame refraction

d. Assessment of contrast sensitivity (ideally)

e. Assessment of binocularity when indicated

f. Assessment of visual fields when indicated

g. Assessment of colour vision when indicated

h. Glare assessment when indicated

i. Assessment of magnification, tint, lighting, environmental requirements

j. Development of rehabilitation plan 
The optometrist should also

- Have a basic acquaintance with accessibility features on common electronic devices (iPad, cell phones, computers, tablets)

- Be able to demonstrate basic sighted guide

- Be able to discuss non-optical approaches and tips for daily living tasks and environmental modifications

- Be able to discuss issues such as driving and transportation options

- Be aware of when patients, either due to their level of vision loss, particular goals, age, or co-morbidities, require more than basic VLR.

- Be able to recognise psychological factors which may influence the adjustment to vision loss and potential for rehabilitation and refer for counselling if needed.

- Refer the patient for fully comprehensive LVR to other professionals and support organisations as indicated, for example, if the patient does not achieve his/her own goals with the LVR provided at this Level.

LEVEL 3 (COMPREHENSIVE LVR) IS ANYTHING BEYOND LEVEL 2

The Optometric LVR provider should have advanced knowledge of LVR to address complex patient presentations and provide full scope LVR. LVR at this level also includes LVR providers who are involved in multidisciplinary care, even though those LVR providers may not necessarily be in the same building.

Patients who are likely to need this level of LVR are

- VA poorer than $6 / 21$

- $\mathrm{CS}<1.00$

- Hemianopia or quadrantanopia and visual fields smaller than 70 degrees ${ }^{1}$ circular field

- Significant central or paracentral scotoma

\section{Minimum additional equipment and devices:}

In addition to the equipment, devices and approaches listed above, the OD LVR provider would have access to a full range of

- higher levels of magnification

- complex magnification systems

- Custom microscopes

- Bioptics and other custom telescopes

- Telemicroscopes

- Head borne devices (optical and video)

- Electro-optical magnification

- prisms

- field enhancement devices

- tints

- Lux metre for lighting measurement

- electronic magnification. 
The LV optometrist should

- be able to implement eccentric viewing training, strategies for field loss,

- be familiar with support groups

- be familiar with Activities of Daily Living Skills (ADLs)

- initiate/direct patients to social assistive services (transport options, meal provision, disability tax credit registration, legal blindness registration) and make recommendations accordingly

- be capable of providing recommendations for school

The OD LVR provider should initiate appropriate referrals and communicate the rehabilitation plan, including but not limited to synopsis of exam findings, final $\mathrm{Rx}$, assistive devices that are recommended and already dispensed, other device recommendations, anticipated performance with devices, training recommendations, environmental modifications, counselling and any referrals recommended or initiated.

The OD LVR provider should have working relationships with and/or refer to:

- Low vision therapist or occupational therapist

- Independent living skills provider or occupational therapist

- Orientation and mobility instructor

- High tech/CCTV/computer assessors

- Optician

- Counsellor/Psychologist

- Vision Resource/Itinerant Teachers/Teachers for the Visually Impaired

- Primary eye-care providers (referring optometrists and ophthalmologists) and other members in the patients circle of care (family physician)

Acknowledgements: Drs Julie-Andre Marinier, Alanna Stetson and Alexis Keeling for reviewing the text. 
Alternative mechanisms for provision of level 3 low vision rehabilitation. ${ }^{11}$

\begin{tabular}{|c|c|c|c|}
\hline $\begin{array}{l}\text { A. Ideal - } \\
\text { multidisciplinary } \\
\text { clinic (MDC) } \\
\text { rehabilitation }\end{array}$ & \multicolumn{2}{|c|}{$\begin{array}{l}\text { B. Second option (second most favourable) - Optometrist and vision } \\
\text { therapist working together }\end{array}$} & $\begin{array}{l}\text { C. Third option } \\
\text { (least favourable, } \\
\text { but maybe necessary } \\
\text { in some locations) }\end{array}$ \\
\hline \multirow{13}{*}{$\begin{array}{l}\text { The MDC is the } \\
\text { ideal environment } \\
\text { for rehabilitation } \\
\text { of these patients } \\
\text { as it is generally } \\
\text { recognised that a } \\
\text { single profession } \\
\text { cannot meet all the } \\
\text { needs of people } \\
\text { with low vision. } \\
\text { In these clinics, } \\
\text { vision therapists, } \\
\text { optometrists/ } \\
\text { ophthalmologists, } \\
\text { opticians, O\&M } \\
\text { trainers, hi-tech } \\
\text { assessment } \\
\text { specialists, } \\
\text { counsellors and } \\
\text { others work } \\
\text { in parallel and } \\
\text { in the same } \\
\text { location to create } \\
\text { a rehabilitation } \\
\text { plan, assess for and } \\
\text { prescribe the full } \\
\text { range of optical } \\
\text { and electronic } \\
\text { devices, address } \\
\text { environmental } \\
\text { modifications, } \\
\text { train in device } \\
\text { use, and train in } \\
\text { sight substitution } \\
\text { techniques. }\end{array}$} & \multicolumn{2}{|c|}{$\begin{array}{l}\text { Since MDC are not universally available this is a second option. A vision therapist } \\
\text { (e.g., VLRC low vision specialist) may undertake assessments in an optometrist's } \\
\text { office or the optometrist may undertake assessments in the vision therapist / } \\
\text { CNIB office. The assessments are undertaken in collaboration (same location, } \\
\text { same patient visit). The way in which roles would be interrelated is shown below. } \\
\text { Other assessments would be planned as required, e.g., O\&M training, home visits. }\end{array}$} & \multirow{13}{*}{$\begin{array}{l}\text { The optometrist } \\
\text { provides the } \\
\text { initial assessment } \\
\text { (refraction, VA, } \\
\text { CS, fields), optical } \\
\text { magnification, } \\
\text { advice re lighting, } \\
\text { filters, prisms, and } \\
\text { training with the } \\
\text { devices provided. } \\
\text { The optometrist } \\
\text { would also be } \\
\text { involved in other } \\
\text { training, such as } \\
\text { eccentric viewing } \\
\text { training and some } \\
\text { counselling around } \\
\text { vision loss. The } \\
\text { optometrist refers to } \\
\text { a vision therapist/ } \\
\text { CNIB VLRC for } \\
\text { other resources and } \\
\text { rehabilitation, such } \\
\text { as O\&M, home visits, } \\
\text { sight-substitution, } \\
\text { training in adaptive } \\
\text { techniques, } \\
\text { counselling and } \\
\text { support groups. The } \\
\text { vision therapist/ } \\
\text { VLRC sends a } \\
\text { report back to the } \\
\text { optometrist of what } \\
\text { interventions they } \\
\text { have undertaken. } \\
\text { In this model, the } \\
\text { patient may enter } \\
\text { the system at VLRC. } \\
\text { In this case, VLRC } \\
\text { would request a } \\
\text { report of visual } \\
\text { function from the } \\
\text { optometrist, initiate } \\
\text { rehabilitation and } \\
\text { then refer to the } \\
\text { optometrist for } \\
\text { vision devices. } \\
\text { The optometrist } \\
\text { would send a report } \\
\text { back to CNIB } \\
\text { outlining his/her } \\
\text { interventions and } \\
\text { recommendations. }\end{array}$} \\
\hline & \multicolumn{2}{|c|}{ Optometrist and LV therapist collaborative assessment (in time sequence) } & \\
\hline & Optometrist & LV therapist & \\
\hline & & $\begin{array}{l}\text { Case history/intake (goals, } \\
\text { disabilities, current devices) }\end{array}$ & \\
\hline & $\begin{array}{l}\text { Refraction, VA (including Near VA), CS, } \\
\text { fields }\end{array}$ & & \\
\hline & $\begin{array}{l}\text { Magnification estimation and suggested } \\
\text { devices for both distance and near }\end{array}$ & & \\
\hline & $\begin{array}{l}\text { Trial of spectacle-mounted devices, } \\
\text { prisms as indicated }\end{array}$ & $\begin{array}{l}\text { Trial of other magnifying optical } \\
\text { devices, possible modification of } \\
\text { magnification }\end{array}$ & \\
\hline & & Tint trials & \\
\hline & & $\begin{array}{l}\text { Assessment for video and computer } \\
\text { devices if indicated }\end{array}$ & \\
\hline & Decision of recommended devices and $\mathrm{p}$ & scription & \\
\hline & & $\begin{array}{l}\text { Training with recommended } \\
\text { devices }\end{array}$ & \\
\hline & & $\begin{array}{l}\text { Assessment for lighting } \\
\text { requirements }\end{array}$ & \\
\hline & & $\begin{array}{l}\text { Assessment for non-optical devices, } \\
\text { e.g., writing aids, daily living aids, etc. }\end{array}$ & \\
\hline
\end{tabular}

VLRC = Vision Loss Rehabilitation Canada, MDC: multidisciplinary clinic, O\&M; orientation and mobility training 
Appendix D

\section{Estimating Magnification}

\section{MAGNIFICATION FOR NEAR}

There are several ways to estimate starting magnification for near. Three common methods are described below.

1. Acuity Reserve: According to Lovie-Kitchin and Whittaker, in order for a low vision patient to read fluently, an acuity reserve needs to be considered ${ }^{7}$. They found that an acuity reserve of 2:1 (or a three-line difference) was effective in helping patients achieve fluent reading (approx. $100 \mathrm{wpm}$ ). An estimate of the required near magnification and equivalent viewing power is typically based on near word reading acuity including this acuity reserve. For adults who want to read, this is typically $2 \mathrm{x}$. The target or goal print size of the patient is determined in equivalent $\mathrm{M}$ print (either by questioning or based on samples brought by the patient). Thus, the magnification required is $2 \mathrm{x}$ the ratio of the visual acuity/target print.

$$
\text { Mag }=2 * \frac{\text { measured acuity in } M \text { print }}{\text { target print size in } M \text { print }}
$$

A typical target print size goal is $1 \mathrm{M}$ or the equivalent of newspaper print. For spot reading (40 wpm), a 1.3:1 (one line) minimal acuity reserve has been suggested, while 3:1 to 8.1:1 may be required for maximum reading rate. ${ }^{1}$

2. Critical Print Size (CPS): An alternative method to estimate required magnification is to measure the reading rate of the patient with variable print sizes. The smallest print that provides maximum reading rate is known as the critical print size. ${ }^{1}$ In this case, there is no need to include the acuity reserve.

$$
M a g=\frac{C P S \text { in } M \text { print }}{\text { target print size in } M \text { print }}
$$

After the estimated magnification is calculated, the required equivalent viewing power (EVP, near addition) can then be determined:

$$
\operatorname{EVP}(D)=\operatorname{Mag} * \text { habitual near add }
$$

The habitual near add is the add used when the reading acuity or CPS was measured. This may also be taken as the dioptric distance used when the visual acuity or CPS was measured.

Some will calculate this requirement in terms of Equivalent Viewing Distance (the change in viewing distance that is required for the patient to meet his/her target print) and then determine the reading add or microscope required to focus at that distance. ${ }^{1,186}$ The end result is the same.

Additionally, some patients will not have a typical habitual working distance or require magnification for a nontypical working distance. However, if the correct reading addition is in place when the habitual visual acuity and/or CPS is measured, the calculations above will still be valid.

3. Kestenbaum's Rule: This is a very quick and rudimentary way to identify the starting near addition:

$$
E V P(D)=\frac{1}{\text { distance } V A}
$$

Example: Distance VA $=6 / 18 \quad$ EVP $($ Near Addition $)=3.00 \mathrm{D}$ 
However, this method to calculate the near add from distance VA may underestimate the add required, as it does not include an acuity reserve and assumes that the goal is $1 \mathrm{M}$ print. A modification to the rule, which includes an acuity reserve would be

$$
E V P(D)=2 * \frac{1}{\text { distance } V A}
$$

\section{Estimating a reading addition for pre-presbyopic patients}

1) Determine patient's age.

2) Determine patient's near acuities at habitual working distance.

3) Determine amplitude of accommodation using minimum formula (15-1/4 age)

4) Leave half of the amplitude in reserve = what patient has.

5) Determine dioptric demand at habitual working distance (what patient needs).

6) Subtract what patient has from what patient needs.

7) Example:

10-year-old achieving 0.6M @ 10cm

Amp $=15-10 / 4=12.5 \mathrm{D}$

Half of that is in reserve, leaving only 6.25D available for use

Demand at $10 \mathrm{~cm}$ is $10 \mathrm{D}$

$10-6.25=3.75 \mathrm{D}=$ initial add to demonstrate (round to 3.5 or $4 \mathrm{D}$ )

8) With this add, consider if patient is reading small enough print for age and demands with an acuity reserve (at least $2 \mathrm{x}$ ).

9) If yes, consider prescribing this add.

10) If no, calculate what additional magnification is needed to achieve the target print with an acuity reserve of $2 x$.

11) Aim to decrease the working distance to give this magnification and recalculate the add that you need for this new distance.

12) Example:

Consider the 10-year-old above

With the $3.75 \mathrm{D}$ add $\mathrm{s} /$ he obtains an acuity of $1.6 \mathrm{M}$ which is the required print size for this grade, i.e., there is no acuity reserve.

A further $2 \mathrm{x}$ magnification is needed.

2x magnification means bringing the print twice as close, i.e., to $5 \mathrm{cms}$ (20D distance)

instead of $10 \mathrm{cms}$ (10D).

Available accommodation is still 6.25D.

Reading add for $5 \mathrm{cms}=20-6.25=13.75 \mathrm{D}=$ next add to demonstrate

Alternatively, try a 2x stand magnifier with a large emergent vergence, e.g., the dome magnifier with the original add.

\section{Clinical pearls:}

- This method tends to overestimate the add - you can try reducing it.

- We would normally round up or down to the nearest diopter or half diopter.

\section{MAGNIFICATION FOR DISTANCE}

In determining the magnification for distance, it is not necessary to include an acuity reserve and typically, the target acuity can be $6 / 9$ or $6 / 12$ for distance and $9 \mathrm{M}$ or $12 \mathrm{M}$ at an intermediate distance.

$$
\text { Mag }=\frac{\text { denominator of patient's acuity }}{\text { denominator of target acuity }}
$$

when the numerators are the same. 
Appendix E

\section{Decentration and Base-in Prism Requirements for Microscopes}

Both decentration and base-in prism need to be considered for patients who are binocular and prescribed microscopes for binocular viewing.

\section{Monocular Decentration required (mms per lens)}

\begin{tabular}{|c|c|c|c|c|c|}
\hline & \multicolumn{5}{|c|}{ Add (D) } \\
\hline Distance PD (mms) & +4 & +6 & +8 & +10 & +12 \\
\hline 58 & 2.8 & 4 & 5.2 & 6.2 & 7.1 \\
\hline 60 & 2.9 & 4.2 & 5.3 & 6.4 & 7.3 \\
\hline 62 & 3.0 & 4.3 & 5.5 & 6.6 & 7.6 \\
\hline 64 & 3.1 & 4.5 & 5.7 & 6.8 & 7.8 \\
\hline 66 & 3.2 & 4.6 & 5.9 & 8.0 & 8.1 \\
\hline 68 & 3.3 & 4.7 & 6.0 & 7.2 & 8.3 \\
\hline
\end{tabular}

Guideline: You can also estimate this from a guideline which states that the total decentration should be $1.5 \mathrm{~mm}$ of decentration per Dioptre of add. If the Distance PD is $>65 \mathrm{~mm}$, then this rule is adjusted by adding $1 \mathrm{~mm}$ to the total decentration, i.e., $1.5 \mathrm{~mm}$ per Dioptre +1 . This guideline gives a fairly accurate estimation. In the case of bifocals, this must be prescribed as additional inset.

Total Convergence demand in prism dioptres

\begin{tabular}{|c|c|c|c|c|c|}
\hline & \multicolumn{5}{|c|}{ Add (D) } \\
\hline Distance PD $(\mathrm{mm})$ & +4 & +6 & +8 & +10 & +12 \\
\hline 58 & 20.9 & 29.9 & 38.0 & 45.7 & 52.5 \\
\hline 60 & 21.7 & 31.0 & 39.5 & 47.2 & 54.4 \\
\hline 62 & 22.4 & 32.0 & 41.0 & 48.8 & 56.2 \\
\hline 64 & 23.1 & 33.0 & 42.0 & 50.4 & 58.0 \\
\hline 66 & 23.8 & 34.0 & 43.5 & 52.0 & 60.0 \\
\hline 68 & 24.5 & 35.0 & 44.7 & 53.5 & 62.0 \\
\hline
\end{tabular}

Guideline: One guideline specifies to prescribe $1 \mathrm{pd}$ BI per eye for each Dioptre of add +2 . For example, if prescribing a $10 \mathrm{D}$ add, 12pd BI per eye would be required. Note that this does NOT fully relieve the convergence demand as shown in the table above, but it is sufficient for most patients. The BI prism of prism half-eyes is according to this guideline. 
Appendix F

\section{Optics of Hand Magnifiers, Stand Magnifiers and Telemicroscopes}

\section{HAND MAGNIFIERS}

\section{Equivalent power (EVP) obtained from a 20D hand magnifier without and with a 4D add}

When a hand magnifier is used without a reading addition or accommodation, the equivalent power of the hand magnifier (and magnification) is independent of the distance between the hand magnifier and the spectacle lens (shown by triangles above).

When the hand magnifier is used with a reading addition or accommodation, an optical system of two lenses is created. The equivalent power (and magnification) of the system increases as the distance between the hand magnifier and the spectacle lens decreases (squares in the figure above). When the hand magnifier is held closer than its own focal distance, the equivalent power of the system is greater than the power of the hand magnifier itself.

In both cases the field of view increases as the hand magnifier is brought closer to the spectacle lens.

\section{EVP as a function of distance between the eye and the hand magnifier}

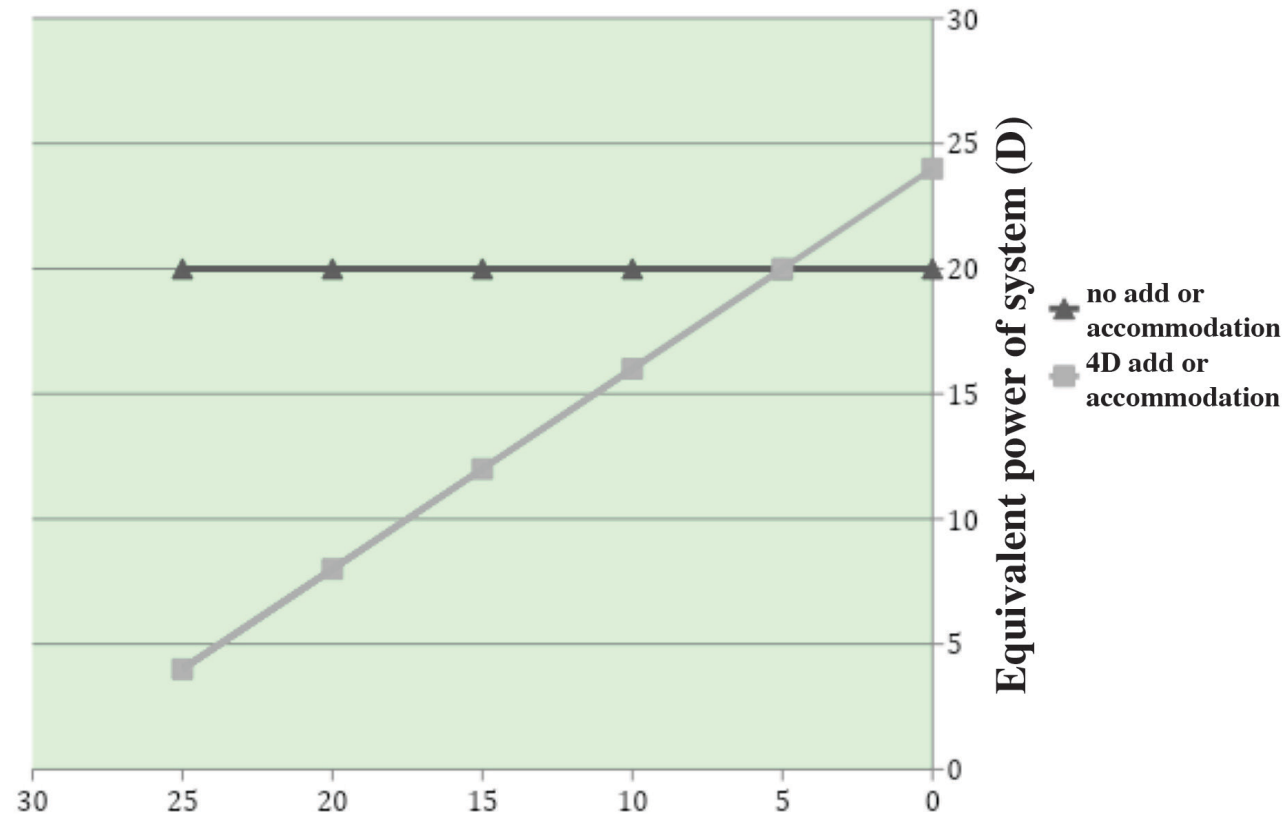

Distance between spectacle lens and magnifier (cms) 


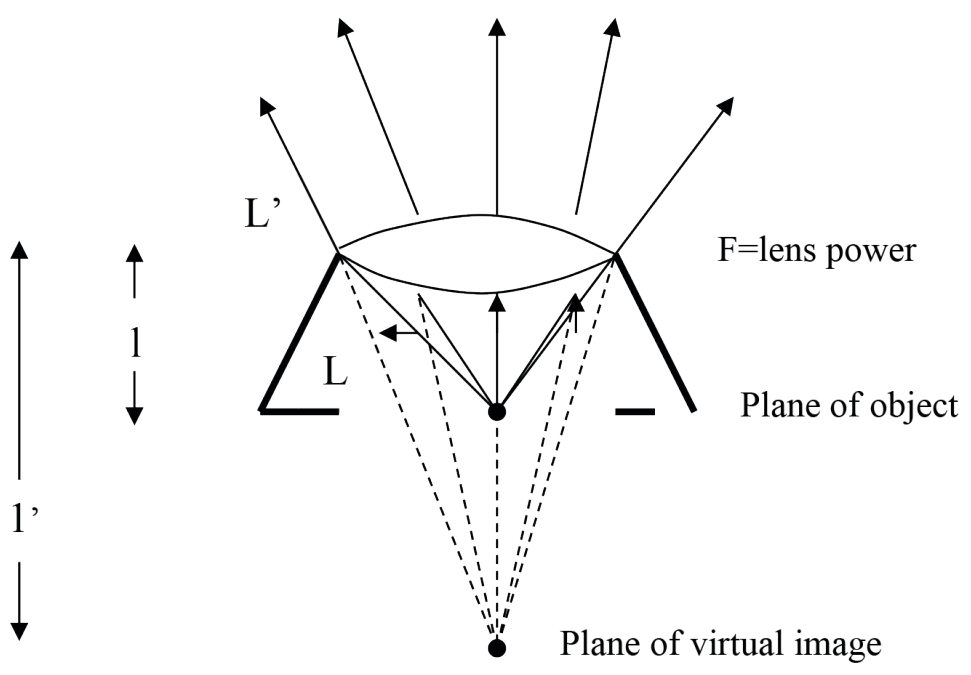

where l' = image distance, 1 = object distance (stand height)

Transverse magnification of Stand magnifiers

The transverse magnification of a stand magnifier can be calculated from the emergent vergence (L') and the power of the lens (F). All values are entered as positive values. The manufacturer's lens powers are quite accurate and can be used in this equation. The L' must be measured or found from look-up tables.

$$
T_{M}=\frac{L^{\prime}+F}{L^{\prime}}
$$

\section{Equivalent power (EVP) of stand magnifiers}

$$
\operatorname{EVP}(D)=\text { Reading add } * T_{M}
$$

where $T_{M}$ is the transverse magnification of the stand magnifier

If the reading addition is to be changed, while maintaining the same EVP, the new transverse magnification is given by the relationship

$$
\text { New Reading Add } * \text { New } T_{M}=\text { Previous Reading Add } * \text { Previous } T_{M}
$$

so that

$$
\text { New } T_{M}=\frac{\text { Previous Add }}{\text { New Add }} * \text { Previous } T_{M}
$$


TELEMICROSCOPES

\section{Equivalent viewing power (EVP) of a telemicroscope}

A telemicroscope is optically composed of an afocal telescope with a positive lens (reading cap) placed on the objective lens to focus it closer than infinity. The "tele" portion is the telescope and the "microscope" portion is the reading cap. The reading cap may be a separate removable lens, or may be integrated into the objective lens.

The required EVP can be determined as described in Appendix D and the EVP of the telemicroscope (EVPTMS) is the product of the reading cap and the magnification of the afocal telescope.

$$
E V P_{T M S}=F_{C} * M_{T S}
$$

where $\mathrm{F}_{\mathrm{C}}$ is the power of the reading cap on the telescope and MTS = the magnification of the telescope.

Alternatively, if the patient's acuity is measured at the final required viewing distance of the telemicroscope (i.e., the distance doesn't change), the magnification can be calculated as in Appendix D by the following formula:

$$
\text { Mag }=2 * \frac{\text { measured acuity in } M \text { print }}{\text { target print size in M print }}
$$

and this will give the magnification of the telemicroscope that is required. Note that not all tasks may require a $2 \mathrm{x}$ acuity reserve. 


\section{Appendix G}

\section{Steps in Eccentric Viewing Training}

1. Central visual field measurement to determine the size and shape of the central scotoma (see methods of visual field measurement listed in section 3.1.6 Visual Fields)

2. Determination of the probable optimal direction of eccentric fixation. This is the area of the visual field, which has the best horizontal extent to the right and which is closest to the anatomical fovea (so has best VA). This location is expected to be ideal for reading in English or other scripts which read left-to-right. The optimal direction of eccentric fixation may be different for scripts which read right-to-left or top-tobottom.

3. Demonstration and trial with the new PRL using the Amsler charts, and samples of graded printed letters and text, such as Quillman's exercises

4. Take-home training

5. Follow-up in 2-3 weeks

6. Demonstration of steady eye strategy, whereby the eccentric viewing position is maintained and the print is scrolled through the PRL.

7. Follow-up after additional home training with assessment of magnification and prescription of devices. 
Appendix $\mathrm{H}$

\section{Placement of Prisms for Peripheral Awareness in Hemianopia}

\section{SECTOR (SPOTTING PRISMS)}

Fresnel prisms are placed on both lenses with their base towards the field defect (example is for right hemianopia), so that the patient does not view through the prism in the primary position, but encounters the prism when they make a small eye movement towards their hemianopia. Both prisms must be placed at the same position relative to the pupil centre, so that both are encountered with the same eye movement. For a hemianopia with no macular sparing, prisms are commonly placed halfway between the pupil edge and limbus. Typically, 20-30pd is used.

If the patient is wearing a bifocal or PAL lens, the prism is cut around the area of the near addition, so that it does not interfere with reading.

\section{Diagrammatic representation of sector prisms for a right hemianopia}

\section{Base Right (out) Base Right (in)}

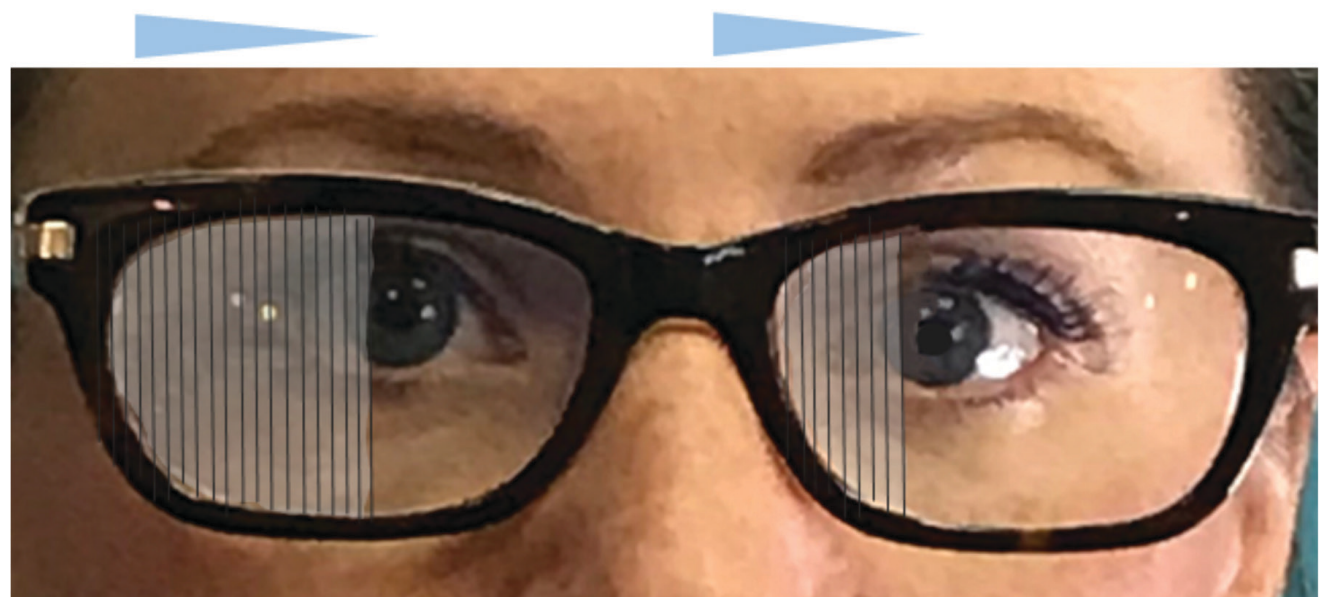

VISUAL DUPLEXING (PELI) PRISMS

These prisms are placed on the lens on the side of the hemianopia above and below fixation, with the base towards the visual field loss. The patient does not fixate through the prism, but is made aware of objects on the side of their hemianopia in their upper and lower visual field. When the patient wishes to identify an object, they turn their head to view through the central zone of the lens. The typical power is $40 \mathrm{pd}$.

As with sector prisms, the prism does not cover the bifocal area, so if the patient requires a bifocal, a small bifocal segment, such as a straight top bifocal, is placed beneath the lower prism. 


\section{Diagrammatic representation of Peli prisms for a right hemianopia}

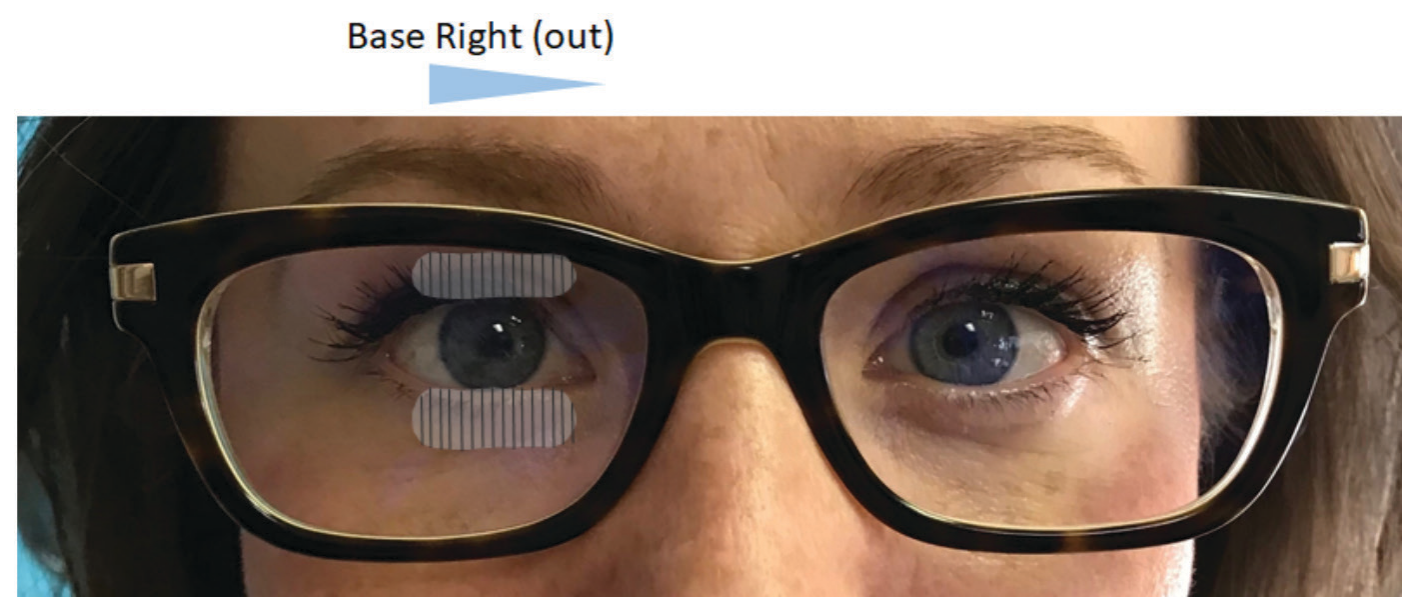

For any of these prisms, training is essential for patient success.

Appendix I

Converting Lux to Lumens

\begin{tabular}{|c|c|c|c|c|c|c|}
\hline Lux required by patient & \multicolumn{5}{|l|}{$\begin{array}{l}\text { Lumens required according to Lux required by patient and anticipated distance of light } \\
\text { source from page }\end{array}$} \\
\hline $\begin{array}{c}\text { Lux required by patient } \\
\text { measured in LV assessment }\end{array}$ & $30 \mathrm{~cm}$ & $40 \mathrm{~cm}$ & $50 \mathrm{~cm}$ & $60 \mathrm{~cm}$ & $70 \mathrm{~cm}$ \\
\hline 500 & 370 & 660 & 1030 & 1485 & 2020 & 2640 \\
\hline 1000 & 740 & 1320 & 2065 & 2970 & 4045 & 5285 \\
\hline 1500 & 1115 & 1980 & 3100 & 4460 & 6070 & 7930 \\
\hline 2000 & 1485 & 2640 & 4130 & 5945 & 8090 & 10570 \\
\hline 2500 & 1860 & 3300 & 5160 & 7430 & 10116 & 13210 \\
\hline 3000 & 2230 & 3965 & 6195 & 8920 & 12140 & 15855 \\
\hline 3500 & 2600 & 4625 & 7225 & 10400 & 14165 & 18500 \\
\hline 4000 & 2970 & 5285 & 8260 & 11890 & 16186 & 21140 \\
\hline 4500 & 3345 & 5945 & 9290 & 13380 & 18210 & 23780 \\
\hline 5000 & 3715 & 6605 & 10320 & 14865 & 20230 & 26425 \\
\hline
\end{tabular}

Note: The patient's preferred Illumination in Lux is measured during the LV assessment. This table can then be used to advise the light source that the patient needs to purchase in terms of light output (Lumens). Table adapted from Borden ${ }^{187}$ 


\section{REFERENCES}

1. Lovie-Kitchin J. Reading with low vision: The impact of research on clinical management. Clin Exp Optom. 2011;94(2):121-132.

2. Legge GE. Psychophysics of reading in normal and low vision. Mahwah, New Jersey: Lawrence Erlbaum Associates Inc.; 2007.

3. Cheong AMY, Legge GE, Lawrence MG, Cheung SH, Ruff MA. Relationship between slow visual processing and reading speed in people with macular degeneration. Vision Res. 2007;47(23):2943-2955.

4. American Academy of Ophthalmology. The Academy's Initiative in Vision Rehabilitation. https://www.aao.org/low-vision-and-visionrehab. Accessed Oct/2, 2018.

5. Leat SJ, Legge GE, Bullimore MA. What is low vision? A re-evaluation of definitions. Optom Vis Sci. 1999;76(4):198-211.

6. American Academy of Ophthalmology. Vision Rehabilitation Preferred Practice Pattern. https://www.aaojournal.org/article/S01616420(17)32957-3/pdf. Accessed Oct/2, 2018.

7. Crossland MD, Engel SA, Legge GE. The preferred retinal locus in macular disease: Toward a consensus definition. Retina. 2011;31(10):2109-2114.

8. The ICF Functioning and Disability Reference Group. The ICF: An Overview. https://www.wcpt.org/sites/wcpt.org/files/files/GHICF_overview_FINAL_for_WHO.pdf. Accessed October, 1st, 2018.

9. World Health Organization. International classification of impairments, disabilities, and handicaps: a manual of classification relating to the consequences of disease, Geneva, Switzerland. https:// apps.who.int/iris/bitstream/handle/10665/41003/9241541261_eng. pdf.;jsessionid=8F85D366E1E3526CBF9AA544B43B5303?sequen ce $=1$. Accessed May 29th, 2019.

10. Maberley D, Hollands H, Chuo J, et al. The prevalence of low vision and blindness in Canada. Eye. 2006;20(3):341-346.

11. Jackson. ML. Vision rehabilitation for Canadians with less than 20/40 acuity: the SmartSight model. Can J Ophthalmol. 2006;41:355-361.

12. Lovie-Kitchin J, Soong G, Hassan S, Woods R. Visual Field Size Criteria for Mobility Rehabilitation Referral. Optom Vis Sci. 2010;87:E948-E957.

13. Lovie-Kitchin J. Low Vision. In: Rosenfield M. LN, ed. Optometry: Science, Techniques and Clinical Management. 2nd ed. Edinburgh; New York: Butterworth Heinemann/Elsevier; 2009:475-497.

14. Rubin G, Rocher K, Prasda-Rao P, Fried L. Vision impairment and disability in older adults. Optom Vis Sci. 1994;71(12):750-760.

15. West SK, Rubin GS, Broman AT, Munoz B, Bandeen-Roche K, Turano K. How does visual impairment affect performance on tasks of everyday life? The SEE Project. Salisbury Eye Evaluation. Arch Ophthalmol. 2002;120(6):774-780.

16. Aljied R, Aubin M-, Buhrmann R, Sabeti S, Freeman EE. Prevalence and determinants of visual impairment in Canada: cross-sectional data from the Canadian Longitudinal Study on Aging. Can J Ophthalmol. 2018;53(3):291-297.

17. Klein R, Klein BEK, Lee KE, Cruickshanks KJ, Chappell RJ. Changes in visual acuity in a population over a 10-year period: The Beaver Dam Eye Study. Ophthalmology. 2001;108(10):1757-1766.

18. Rubin GS, West SK, Muñoz B, et al. A comprehensive assessment of visual impairment in a population of older Americans: The SEE Study. Invest Ophthalmol Vis Sci. 1997;38(3):557-568.

19. Attebo K, Mitchell P, Smith W. Visual acuity and the causes of visual loss in Australia: The Blue Mountains Eye Study. Ophthalmology. 1996;103(3):357-364.

20. Chan T, Friedman DS, Bradley C, Massof R. Estimates of incidence and prevalence of visual impairment, low vision, and blindness in the United States. JAMA Ophthalmol. 2018;136(1):12-19.

21. Statistics Canada. An Aging Population. https://wwwl50.statcan. gc.ca/nl/pub/11-402-x/2010000/chap/pop/pop02-eng.htm. Accessed March/14, 2019.

22. Public Health Agency of Canada. 2011. Diabetes in Canada: Facts and figures from a Public Health Perspective. http://www.phacaspc.gc.ca/cd-mc/publications/diabetes-diabete/facts-figures-faitschiffres-2011/pdf/facts-figures-faits-chiffres-eng.pdf. Accessed March/14, 2019.

23. Goldstein JE, Massof RW, Deremeik JT, et al. Baseline traits of low vision patients served by private outpatient clinical centers in the United States. Arch Ophthalmol. 2012;130(8):1028-1037.
24. Stelmack JA, Tang XC, Wei Y, et al. Outcomes of the veterans affairs low vision intervention trial II (LOVIT II) a randomized clinical trial. JAMA Ophthalmol. 2017;135(2):96-104.

25. Kempen GIJM, Ballemans J, Ranchor AV, Van Rens GHMB, Zijlstra GAR. The impact of low vision on activities of daily living, symptoms of depression, feelings of anxiety and social support in community-living older adults seeking vision rehabilitation services. Qual Life Res. 2012;21(8):1405-1411.

26. Owsley C, McGwin G. Vision and driving. Vis Res. 2010;50(23):2348-2361.

27. Statistics Canada. Facts on seeing limitations. https://www150.statcan.gc.ca/nl/pub/89-628-x/2009013/fs-fi/fs-fi-eng.htm. Accessed May 29th, 2019.

28. O'Day B. Employment barriers for people with visual impairments. J Vis Impair Blind. 1999;93(10):627-642.

29. Sherrod CE, Vitale S, Frick KD, Ramulu PY. Association of vision loss and work status in the United States. JAMA Ophthalmol. 2014;132(10):1239-1242.

30. Lord SR, Smith ST, Menant JC. Vision and falls in older people: risk factors and intervention strategies. Clin Geriatr Med. 2010;26(4):569-581.

31. Elliott DB. The Glenn A. Fry award lecture 2013: Blurred vision, spectacle correction, and falls in older adults. Optom Vis Sci. 2014;91(6):593-601.

32. Ivers RQ, Cumming RG, Mitchell P, Attebo K. Visual impairment and falls in older adults: The Blue Mountains Eye Study. J Am Geriatr Soc. 1998;46(1):58-64.

33. Senra H, Barbosa F, Ferreira P, et al. Psychologic adjustment to irreversible vision loss in adults: A systematic review. Ophthalmology. 2015;122(4):851-861.

34. Burmedi D, Becker S, Heyl V, Wahl H-, Himmelsbach I. Emotional and social consequences of age-related low vision. Vis Impair Res. 2002;4(1):47-71.

35. Horowitz A. The prevalence and consequences of vision impairment in later life. Top Geriatr Rehabil. 2004;20(3):185-195.

36. Waern M, Rubenowitz E, Runeson B, Skoog I, Wilhelmson K, Allebeck P. Burden of illness and suicide in elderly people: Case-control study. Br Med J. 2002;324(7350):1355-1357.

37. McCarty CA, Nanjan MB, Taylor HR. Vision impairment predicts 5 year mortality. Br J Ophthalmol. 2001;85(3):322-326.

38. Zheng D, Christ SL, Lam BL, Arheart KL, Galor A, Lee DJ. Increased mortality risk among the visually impaired: The roles of mental well-being and preventive care practices. Invest Ophthalmol Vis Sci. 2012;53(6):2685-2692.

39. Lam N, Leat SJ. Barriers to accessing low vision care: the patient's perspective. Can J Ophthalmol. 2013;48(6):458-462.

40. Gresset J, Baumgarten M. Prevalence of visual impairment and utilization of rehabilitation services in the visually impaired elderly population of Quebec. Optom Vis Sci. 2002;79(7):416-423.

41. Overbury O, Wittich W. Barriers to low vision rehabilitation: The Montreal Barriers Study. Invest Ophthalmol Vis Sci. 2011;52(12):8933-8938.

42. Spafford MM, Rudman DL, Leipert BD, Klinger L, Huot S. When self-presentation trumps access: why older adults with low vision go without low-vision services. J App Ger. 2009;29:579-602.

43. Nia K, Markowitz SN. Provision and utilization of low-vision rehabilitation services in Toronto. Can J Ophthalmol. 2007;42(5):698-702.

44. Leat SJ, Rumney NJ. The experience of a university-based low vision clinic. Ophthal Physiol Opt. 1990;10(1):8-15.

45. Margrain TH. Helping blind and partially sighted people to read: the effectiveness of low vision aids. Br J Ophthalmol. 2000;84(8):919-921.

46. Binns AM, Bunce C, Dickinson C, et al. How effective is low vision service provision? A systematic review. Surv Ophthalmol. 2012;57(1):34-65.

47. Raasch TW, Leat SJ, Kleinstein RN, Bullimore MA, Cutter GR. Evaluating the value of low-vision services. J Am Optom Assoc. 1997;68(5):287-295.

48. Ryan B, Khadka J, Bunce C, Court H. Effectiveness of the community-based Low Vision Service Wales: A long-term outcome study. Br J Ophthalmol. 2013;97(4):487-491.

49. DeCarlo DK, McGwin G, Searcey K, et al. Use of prescribed optical devices in age-related macular degeneration. Optom Vis Sci. 2012;89(9):1336-1342. 
50. Ryan B, White S, Wild J, Court H, Margrain. TH. The newly established primary care based Welsh Low Vision Service is effective and has improved access to low vision services in Wales. Ophthal Physiol Opt. 2010;30(4):358-364.

51. Kuyk T, Liu L, Elliott JL, et al. Health-related quality of life following blind rehabilitation. Qual Life Res. 2008;17(4):497-507.

52. Scott IU, Smiddy WE, Schiffman J, Feuer WJ, Pappas CJ. Quality of life of low-vision patients and the impact of low-vision services. Am J Ophthalmol. 1999;128(1):54-62.

53. Langelaan M, De Boer MR, Van Nispen RMA, Wouters B, Moll AC, Van Rens GHMB. Change in quality of life after rehabilitation: Prognostic factors for visually impaired adults. Int $\mathrm{J}$ Rehabil Res. 2009;32(1):12-19.

54. Wolffsohn JS, Cochrane AL. Design of the low vision quality-of-life questionnaire (LVQOL) and measuring the outcome of low-vision rehabilitation. Am J Ophthalmol. 2000;130(6):793-802.

55. De Boer MR, Twisk J, Moll AC, Völker Dieben HJ, De Vet HC, Van Rens GH. Outcomes of low vision services using optometric and multidisciplinary approaches: a non randomized comparison. Ophthal Physiol Opt. 2006;26(6):535-544.

56. Hinds A, Sinclair A, Park J, Suttie A, Paterson H, Macdonald M. Impact of an interdisciplinary low vision service on the quality of life of low vision patients. Br J Ophthalmol. 2003;87(11):1391-1396.

57. Stelmack JA, Tang XC, Reda DJ, Rinne S, Mancil RM, Massof RW. Outcomes of the veterans affairs low vision intervention trial (LOVIT). Arch Ophthalmol. 2008;126(5):608-617.

58. Stelmack JA, Szlyk JP, Stelmack TR, Demers-Turco P, Williams RT, Massof RW. Measuring outcomes of vision rehabilitation with the Veterans Affairs Low Vision Visual Functioning Questionnaire. Invest Ophthalmol Vis Sci. 2006;47(8):3253-3261.

59. Court H, Ryan B, Bunce C, Margrain TH. How effective is the new community-based Welsh low vision service? $\mathrm{Br} \mathrm{J}$ Ophthalmol. 2011;95(2):178-184.

60. Leat SJ, Fryer A, Rumney NJ. Outcome of low vision aid provision: the effectiveness of a low vision clinic. Optom Vis Sci. 1994;71(3):199-206.

61. Ryan. B. Models of low vision care: Past, present and future. Clin Exp Optom. 2014;97(3):209-213.

62. Gustafsson J, Inde K. The history and current status of low vision services in Scandinavian countries. J Vis Imp Blind. 2009;103(9):558-562.

63. Lawrence M. Low Vision Care -The Kooyong Experience. J Vis Imp Blind. 1985;79(8):337-340.

64. La Grow S, Daye P. A comparison of comprehensive low vision services to those services normally available to older persons with visual impairments in New Zealand. Int Cong Ser. 2005;1282:187-190.

65. Reeves BC, Harper RA, Russell WB. Enhanced low vision rehabilitation for people with age related macular degeneration: a randomised controlled trial. Br J Ophthalmol. 2004;88(11):1443-1449.

66. World Health Organization. Vision 2010: The Right to Sight. Asia Pacific Regional Low Vision Workshop. http://whqlibdoc.who.int/ Hq/2002/WHO_PBL_02.87.pdf. Accessed Dec/29, 2014.

67. American Academy of Ophthalmology. Preferred Practice Pattern for Vision Rehabilitation. http://www.aao.org/preferred-practicepattern/vision-rehabilitation-ppp--2013. Accessed Apr 23rd, 2015

68. American Optometric Association. Clinical Practice Guideline: Care of the Patient with Visual Impairment. http://www.aoa.org/documents/optometrists/CPG-14.pdf. Accessed April 23rd, 2015.

69. Gilmour GR. Low vision rehabilitation services: the Saskatchewan experience. Can J Ophthalmol. 2006;41(3):370-372.

70. Gold D, Zuvela B. The impact of health policy gaps on low vision services in Canada. Int Cong Ser. 2005;1282:134-138.

71. Leat SJ. Proposed model for integrated low-vision rehabilitation services in Canada. Optom Vis Sci. 2016;93(1):77-84.

72. Bentley S, Jackson A, Johnston A, et al. Advancing low vision services: A plan for Australian optometry. Clin Exp Optom. 2014;97(3):214-220.

73. Association of Schools and Colleges of Optometry. Entry-level competencies and learning objectives in visual impairment and low vision rehabilitation. https://optometriceducation.org/files/EntryLevelCompetencies_LowVision.pdf. Accessed April 16th, 2019.

74. Gordon K, Bonfanti A, Pearson V, Markowitz SN, Jackson ML, Small L. Comprehensive vision rehabilitation. Can J Ophthalmol. 2015;50(1):85-86.

75. Eye Health Council of Ontario. Low Vision Rehabilitation SubCommittee. Low Vision Services in Ontario: Current Status, Gaps and Recommendations for Change. 2015.
76. Colenbrander A. Visual functions and functional vision. Int Cong Ser. 2005;1282:482-486.

77. Massof RW. A systems model for low vision rehabilitation II. Measurement of vision disabilities. Optom Vis Sci. 1998;75(5):349-373.

78. Massof RW, Hsu CT, Baker FH, et al. Visual disability variables. II: The difficulty of tasks for a sample of low-vision patients. Arch Phys Med Rehabil. 2005;86(5):954-967.

79. Kroenke K, Spitzer RL, Williams JBW. The patient health questionnaire-2: Validity of a two-item depression screener. Med Care. 2003;41(11):1284-1292.

80. Bailey IL, Lovie JE. New design principles for visual acuity letter charts. Optom Vis Sci. 1976;53(11):740-745.

81. Ferris FL, Kassoff A, Bresnick GH, Bailey I. New visual acuity charts for clinical research. Am J Ophthalmol. 1982;94(1):91-96.

82. Bailey IL, Lovie-Kitchin JE. Visual acuity testing. From the laboratory to the clinic. Vis Res. 2013;90:2-9.

83. Hardgrave N, Hatley J, Lewerenz D. Comparing LEA numbers low vision book and Feinbloom visual acuity charts. Optom Vis Sci. 2012;89(11):1611-1618.

84. Bailey IL, Jackson AJ, Minto H, Greer RB, Chu MA. The Berkeley rudimentary vision test. Optom Vis Sci. 2012;89(9):1257-1264.

85. Jolly J, Gray J, Salvetti AP, Han RC, MacLaren RE. A ransomised corss-over study to assess the useablility of two new vision tests in patients with low vision. Optom Vis Sci. 2019;96(6):443-452.

86. Bailey IL, Jackson AJ. Changes in the clinical measurement of visual acuity. J Phys Conf Ser. 2016;772(1).

87. Kushner BJ, Lucchese NJ, Morton GV. Grating visual acuity with Teller cards compared with Snellen visual acuity in literate patients. Arch Ophthalmol. 1995;113(4):485-493.

88. Mayer DL, Fulton AB, Rodier D. Grating and recognition acuities of pediatric patients. Ophthalmology. 1984;91(8):947-953.

89. Calabrèse A, To L, He Y, Berkholtz E, Rafianm P, Legge GE. Comparing performance on the MNREAD iPad application with the MNREAD acuity chart. J Vis. 2018;18(1).

90. Bowers AR, Meek C, Stewart N. Illumination and reading performance in age-related macular degeneration. Clin Exp Optom. 2001;84(3):139-147.

91. Rotruck J, Fletcher DC, Walker L. Low vision patents with AMD and POAG may require different lighting to maximize visual acuity. http://jasperridge.net/wp-content/uploads/2015/03/FletcherARVO-abstract.pdf. Accessed May 30th, 2019.

92. Sunness JS, El Annan J. Improvement of visual acuity by refraction in a low-vision population. Ophthalmology. 2010;117(7):1442-1446.

93. Rubin GS, Legge GE. Psychophysics of reading. VI--The role of contrast in low vision. Vision Res. 1989;29(1):79-91.

94. Whittaker SG, Lovie-Kitchin J. Visual requirements for reading. Optom Vis Sci. 1993;70(1):54-65.

95. Leat SJ, Woo GC. The validity of current clinical tests of contrast sensitivity and their ability to predict reading speed in low vision. Eye. 1997;11(6):893-899.

96. Latham K, Tabrett D. Guidelines for Predicting Performance with Low Vision Aids. Optom Vis Sci. 2012;89:1316-1326.

97. Bowers A. Contrast sensitivity losses impair pedestrian detection more than visual acuity losses. https://www.aaopt.org/detail/knowledge-base-article/contrast-sensitivity-losses-impair-pedestriandetection-more-than-visual-acuity-losses. Accessed May 29th, 2019.

98. Marron JA, Bailey IL. Visual factors and orientation-mobility performance. Am J Optom Physiol Opt. 1982;59(5):413-426.

99. Horswill MS, Marrington SA, McCullough CM, et al. The hazard perception ability of older drivers. J Gerontol Ser B Psychol Sci Soc Sci. 2008;63(4):212-P218.

100. Rubin GS, Bandeen-Roche K, Huang GH, et al. The association of multiple visual impairments with self-reported visual disability: SEE project. Invest Ophthalmol Vis Sci. 2001;42(1):64-72.

101. Barnes CS, De L'Aune W, Schuchard RA. A test of face discrimination ability in aging and vision loss. Optom Vis Sci. 2011;88(2):188-199.

102. Kuyk T, Elliott JL, Fuhr PS. Visual correlates of mobility in real world settings in older adults with low vision. Optom Vis Sci. 1998;75(7):538-547.

103. Lord SR. Visual risk factors for falls in older people. Age Ageing. 2006;35(S2):42-45.

104. Dougherty B, Flom R, Bullimore M. An evaluation of the Mars letter contrast sensitivity test. Optom Vis Sci. 2005;82(11):970-975.

105. Schuchard RA. Validity and Interpretation of Amsler Grid Reports. Arch Ophthalmol. 1993;111(6):776-780.

106. Wall M, May DR. Threshold Amsler Grid Testing in Maculopathies. Ophthalmology. 1987;94(9):1126-1133. 
107. Taylor JJ, Bambrick R, Brand A, et al. Effectiveness of portable electronic and optical magnifiers for near vision activities in low vision: a randomised crossover trial. Ophthal Physiol Opt. 2017;37(4):370-384.

108. Virgili G, Acosta R, Bentley SA, Giacomelli G, Allcock C, Evans JR. Reading aids for adults with low vision. Cochrane Database Syst Rev. 2018;(4),CD003303.

109. Bray N, Brand A, Taylor J, Hoare Z, Dickinson C, Edwards RT. Portable electronic vision enhancement systems in comparison with optical magnifiers for near vision activities: an economic evaluation alongside a randomized crossover trial. Acta Ophthalmol. 2017;95(5):e415-e423.

110. Leat SJ, Si FF, Gold D, Pickering D, Gordon K, Hodge W. The experience of a randomized clinical trial of closed-circuit television versus eccentric viewing training for people with age-related macular degeneration. J Vis Impair Blind. 2017;111(4):354-368.

111. Baldry K, Labreche T, Szilva MM. Visual field loss - end of the road for driving? J Vis Impair Blind. In press.

112. Wittich W, Lorenzini M-, Markowitz SN, et al. The effect of a head-mounted low vision device on visual function. Optom Vis Sci. 2018;95(9):774-784.

113. IrisVision. https://irisvision.com Accessed Oct 31st, 2019.

114. Horus. http://horus.tech/?l=en_us. Accessed Mar 20th, 2019.

115. Orcam. Advanced wearable AI devices for the blind. https://www. orcam.com/en/. Accessed Mar 20th, 2019.

116. Bittner AK, Yoshinaga P, Bowers A, Shepherd JD, Succar T, Ross NC. Feasibility of Telerehabilitation for Low Vision: Satisfaction Ratings by Providers and Patients. Optom Vis Sci. 2018;95(9):865-872

117. Bittner AK, Wykstra SL, Yoshinaga PD, Li T. Telerehabilitation for people with low vision. Cochrane Database Syst Rev. 2015;(8):CD011019.

118. Gaffney AJ, Margrain TH, Bunce CV, Binns AM. How effective is eccentric viewing training? A systematic literature review. Ophthalmic Physiol Opt. 2014;34(4):427-437.

119. Frennesson C, Nilsson SE. The superior retina performs better than the inferior retina when reading with eccentric viewing: A compariso in normal volunteers. Acta Ophthalmol Scand. 2007;85(8):868-870.

120. Fine EM, Rubin GS. Reading with simulated scotomas: attending to the right is better than attending to the left. Vis Res. 1999;39(5):1039-1048.

121. Fletcher DC. Relative locations of macular scotomas near the PRL: Effect on low vision reading. J Rehab Res Dev. 1999;36(4):356-364.

122. Crossland MD, Culham LE, Kabanarou SA, Rubin GS. Preferred retinal locus development in patients with macular disease. Oph thalmology. 2005;112(9):1579-1585.

123. Watson GR, Schuchard RA, De l'Aune WR, Watkins E. Effects of preferred retinal locus placement on text navigation and development of advantageous trained retinal locus. J Rehab Res Dev. 2006;43(6):761-770.

124. Howe J. Eccentric viewing training and its effect on the reading rates of individuals with absolute central scotomas: A meta-analysis. J Vis Impair Blind. 2012;106(9):527-542.

125. Vukicevic M, Fitzmaurice K, eds. Impact of eccentric viewing and magnification interventions on the performance of activities of daily living. Int Cong Ser. 2005;1282:544-548.

126. Verdina T, Giacomelli G, Sodi A, et al. Biofeedback rehabilitation of eccentric fixation in patients with stargardt disease. Eur J Ophthalmol. 2013;23(5):723-731.

127. Kasten E, Haschke P, Meinhold U, Oertel-Verweyen P. A computer program for training eccentric reading in persons with central scotoma. J Vis Impair Blind. 2010;104(5):303-311.

128. Vingolo EM, Cavarretta S, Domanico D, Parisi F, Malagola R. Microperimetric biofeedback in AMD patients. Appl Psychophysiol Biofeedback. 2007;32(3-4):185-189.

129. Seiple W, Grant P, Szlyk JP. Reading rehabilitation of individuals with AMD: Relative effectiveness of training approaches. Invest Ophthalmol Vis Sci. 2011;52(6):2938-2944.

130. Hassan SE, Ross NC, Massof RW, Stelmack J. Changes in the properties of the preferred retinal locus with eccentric viewing training. Optom Vis Sci. 2019;96(2):79-86

131. Giorgi D, Contestabile MT, Pacella E, Gabrieli CB. An instrument for biofeedback applied to vision. Appl Psychophysiol Biofeedback. 2005;30(4):389-395

132. Vingolo EM, Salvatore S, Limoli PG. MP-1 biofeedback: Luminous pattern stimulus versus acoustic biofeedback in age related macular degeneration (AMD). Appl Psychophysiol Biofeedback. 2013;38(1):11-16
133. Amore FM, Paliotta S, Silvestri V, Piscopo P, Turco S, Reibaldi A. Biofeedback stimulation in patients with age-related macular degeneration: Comparison between 2 different methods. Can J Ophthalmol. 2013;48(5):431-437.

134. Lewerenz D, Blanco D, Ratzlaff C, Zodrow A. The effect of prism on preferred retinal locus. Clin Exp Optom. 2018;101(2):260-266.

135. Smith HJ, Dickinson CM, Cacho I, Reeves BC, Harper RA. A randomized controlled trial to determine the effectiveness of prism spectacles for patients with age-related macular degeneration. Arch Ophthalmol. 2005;123(8):1042-1050.

136. Schneck ME, Haegerstrom-Portnoy G, Lott LA, Brabyn JA, Gildengorin G. Low contrast vision function predicts subsequent acuity loss in an aged population: The SKI study. Vis Res. 2004;44(20):2317-2325.

137. Haymes SA, Roberts KF, Cruess AF, et al. The letter contrast sensitivity test: Clinical evaluation of a new design. Invest Ophthalmol Vis Sci. 2006;47(6):2739-2745.

138. Eperjesi F, Fowler CW, Evans BJ. Effect of light filters on reading speed in normal and low vision due to age related macular degeneration. Ophthal Physiol Opt. 2004;24(1):17-25.

139. Bailie M, Wolffsohn JS, Stevenson M, Jackson AJ. Functional and perceived benefits of wearing coloured filters by patients with agerelated macular degeneration. Clin Exp Optom. 2013;96(5):450-454.

140. Bowers AR, Keeney K, Peli E. Community-based trial of a peripheral prism visual field expansion device for hemianopia. Arch Ophthalmol. 2008;126(5):657-664.

141. Nowakowski RW. Primary low vision care. Norwalk, CT: Appleton \& Lange; 1994

142. Wilcox DT, Chronister CL, Savage MR. Methods for prism placement for hemianopic visual field loss in adults with low vision. J Vis Impair Blind. 2016;110(4):276-279.

143. Brilliant RL. Essentials of low vision practice. Butterworth-Heinemann Boston; 1999.

144. Apfelbaum HL, Ross NC, Bowers AR, Peli E. Considering apical scotomas, confusion, and diplopia when prescribing prisms for homonymous hemianopia. Transl Vis Sci Tech. 2013;2(4):1-18.

145. Bagheri A, Abbasi H, Tavakoli M, Sheibanizadeh A, Kheiri B, Yazdani S. Effect of rigid gas permeable contact lenses on nystagmus and visual function in hyperopic patients with infantile nystagmus syndrome. Strabismus. 2017;25(1):17-22.

146. Jayaramachandran P, Proudlock FA, Odedra N, Gottlob I, McLean RJ. A randomized controlled trial comparing soft contact lens and rigid gas-permeable lens wearing in infantile nystagmus. Ophthalmology. 2014;121(9):1827-1836.

147. Bowers AR. Driving with homonymous visual field loss: a review of the literature. Clin Exp Optom. 2016;99(5):402-418.

148. Bergeron CM, Wanet-Defalque M-. Psychological adaptation to visual impairment: The traditional grief process revised. B J Vis Impair. 2013;31(1):20-31.

149. Rees G, Tee HW, Marella M, Fenwick E, Dirani M, Lamoureux EL. Vision-specific distress and depressive symptoms in people with vision impairment. Invest Ophthalmol Vis Sci. 2010;51(6):2891-2896.

150. Chen SP, Bhattacharya J, Pershing S. Association of vision loss with cognition in older adults. JAMA Ophthalmol. 2017;135(9):963-970.

151. Naël V, Pérès K, Dartigues J, et al. Vision loss and 12-year risk of dementia in older adults: the 3C cohort study. Eur J Epidemiol 2019;34(2):141-152

152. Spierer O, Fischer N, Barak A, Belkin M. Correlation between vision and cognitive function in the elderly: A cross-sectional study. Medicine. 2016;95(3); 2423.

153. Reyes-Ortiz CA, Kuo Y-, DiNuzzo AR, Ray LA, Raji MA, Markides KS. Near vision impairment predicts cognitive decline: Data from the Hispanic established populations for epidemiologic studies of the elderly. J Am Geriatr Soc. 2005;53(4):681-686.

154. Rogers MAM, Langa KM. Untreated poor vision: A contributing factor to late-life dementia. Am J Epidemiol. 2010;171(6):728-735.

155. Davies-Kershaw HR, Hackett RA, Cadar D, Herbert A, Orrell M, Steptoe A. Vision Impairment and Risk of Dementia: Findings from the English Longitudinal Study of Ageing. J Am Geriatr Soc. 2018;66(9):1823-1829.

156. Dearborn PJ, Elias MF, Sullivan KJ, Sullivan CE, Robbins MA Poorer Visual Acuity Is Associated with Declines in Cognitive Performance Across Multiple Cognitive Domains: The Maine-Syracuse Longitudinal Study. J Int Neuropsychol Soc. 2018;24(7):746-754. 
157. Lin MY, Gutierrez PR, Stone KL, et al. Vision impairment and combined vision and hearing impairment predict cognitive and functional decline in older women. J Am Geriatr Soc. 2004;52(12):1996-2002.

158. Zheng DD, Swenor BK, Christ SL, West SK, Lam BL, Lee DJ. Longitudinal associations between visual impairment and cognitive functioning, The Salisbury Eye Evaluation Study. JAMA Ophthalmol. 2018;136(9):989-995.

159. Anstey KJ, Luszcz MA, Sanchez L. Two-year decline in vision but not hearing is associated with memory decline in very old adults in a population-based sample. Gerontology. 2001;47(5):289-293.

160. Lin H, Zhang L, Lin D, et al. Visual Restoration after cataract Surgery promotes functional and structural brain recovery. EBioMedicine. 2018;30:52-61.

161. Fukuoka H, Sutu C, Afshari NA. The impact of cataract surgery on cognitive function in an aging population. Curr Op Ophthalmol. 2016;27(1):3-8

162. Ishii K, Kabata T, Oshika T. The impact of cataract surgery on cognitive impairment and depressive mental status in elderly patients. Am J Ophthalmol. 2008;146(3):404-409.

163. Meyniel C, Samri D, Stefano F, et al. COGEVIS: A new scale to evaluate cognition in patients with visual deficiency. Behav Neurol. 2018;4295184.

164. Hagerman KE, Taussig MJ, Coalter JD, Jay WM. Low-vision rehabilitation in patients with visual and cognitive impairment. Vis Imp Res. 2007;9(1):19-22

165. Whitson HE, Whitaker D, Potter G, et al. A low-vision rehabilitation program for patients with mild cognitive deficits. JAMA Ophthalmol. 2013;131(7):912-919.

166. Gervais M-, Couture M, Le Blanc S, Blanchet S, Gagné M-, Ouellet M-. Evaluation of Cognitive Functioning in the Context of Rehabilitation for Visual Impairment in Older Adults: A Case Series. Phys Occup Ther Geriatr. 2017;35(3-4):132-155.

167. Ciner EB, Appel SD, Graboyes M. Low vision special populations 1: The multiply impaired patient. In: Brilliant RL, ed. Essentials of low vision practice. Boston: Butterworth-Heinemann; 1999:313-334.

168. Leat SJ. Pediatric Low Vision - Impact, Assessment and Management. In: Chen AH, Leat SJ, eds. Pediatric Vision Care: current practice and future challenges. Singapore: McGraw-Hill; 2015:209-224.

169. Sanspree MJ. Chapter 62. Pathways to habilitation. In: Silverstone B, Lang MA, Rosenthal BP, Faye EE, eds. The Lighthouse Handbook on Vision Impairment and Vision Rehabilitation. New York: Oxford University Press; 2000:1167-11182.

170. Jackson ML, Wallis J, Schoessow K, Drohan B, Williams K. Visual function in the 'oldest-old' 1 year after comprehensive vision rehabilitation. J Am Geriatr Soc. 2012;60(1):183-185.

171. Peckham A, Al-Ghetaa R, Ho J, Marchildon G. Assistive Devices: Regulation and Coverage in Canada. Rapid Review 4. https://ihpme. utoronto.ca/wp-content/uploads/2018/11/NAO-Rapid-Review-4 EN_new.pdf. Accessed July 30, 2019.

172. Gouvernement du Quebec. Aid Programs. Recognized facilitie specialized in visual aids. http://www.ramq.gouv.qc.ca/en/citizens/ aid-programs/visual-aids/Pages/recognized-specialized-facilities. aspx. Accessed July 30th, 2019.
173. Gouvernement du Quebec. Visual aids. http://www.ramq.gouv. qc.ca/en/citizens/aid-programs/visual-aids/Pages/visual-aids.aspx. Accessed July 30th, 2019.

174. Ontario Ministry of Health and Long Term Care. Assistive Devices Program. https://www.ontario.ca/page/assistive-devices-program Accessed Aug 14th 2019.

175. Government of Alberta. CNIB Specialized Technical Equipment Program. https://www.alberta.ca/assets/documents/aadl/aadlmanual-cnib-step.pdf. Accessed July 30th, 2019.

176. Harper K, McFee C, MacDonald I, Jones M. Low vision service models in Alberta: innovation, collaboration, and future opportunities. Can J Ophthalmol. 2006;41(3):373-377.

177. Saskatchewan. Saskatchewan Aids to Independent Living. https:// www.saskatchewan.ca/residents/health/accessing-health-careservices/health-services-for-people-with-disabilities/sail. Accessed Aug 14th, 2019.

178. Barker L, Thomas R, Rubin G, Dahlmann-Noor A. Optical reading aids for children and young people with low vision. Cochrane Database Syst Rev. 2015;(3):CD010987.

179. Hamade N, Hodge WG, Rakibuz-Zaman M, Malvankar-Mehta MS. The Effects of low-vision rehabilitation on reading speed and depression in age related macular degeneration: A meta-analysis. PLoS ONE. 2016;11(7):e0159254.

180. Jutai JW, Strong JG, Elizabeth R-. Effectiveness of assistive technologies for low vision rehabilitation: A systematic review. J Vis Impair Blind. 2009;103(4):210-222.

181. Liu C, Brost MA, Horton VE, Kenyon SB. Occupational therapy interventions to improve performance of daily activities at home for older adults with low vision: A systematic review. Am J Occup Ther. 2013;67(3):279-287.

182. Rees G, Ponczek E, Hassell J, Keeffe JE, Lamoureux EL. Psychological outcomes following interventions for people with low vision A systematic review. Expert Rev Ophthalmol. 2010;5(3):385-403.

183. Skelton DA, Howe TE, Ballinger C, Neil F, Palmer S, Gray L. Environmental and behavioural interventions for reducing physical activity limitation in community-dwelling visually impaired older people. Cochrane Database Syst Rev. 2013;(6):CD009233.

184. Thomas R, Barker L, Rubin G, Dahlmann-Noor A. Assistive technology for children and young people with low vision. Cochrane Database Syst Rev. 2015;(6):CD011350

185. Virgili G, Rubin G. Orientation and mobility training for adults with low vision. Cochrane Database Syst Rev. 2010;5:CD003935

186. Lovie-Kitchin JE, Whittaker SG. Prescribing near magnification for low vision patients. Clin Exp Optom. 1999;82(6):214-224.

187. Borden $\mathrm{P}$, Klein M. Measuring and prescribing preferred light intensity and color. http://jasperridge.net/wp-content/uploads/2014/10/ R4-Borden-PowerPoint.pdf. Accessed Mar 23rd, 2019. 